\title{
¿Seasonal Covariability of Dryness or Wetness in China and Global Sea Surface Temperature $\mathscr{O}$
}

\author{
CHUNXIANG Li \\ CAS Key Laboratory of Regional Climate-Environment for Temperate East Asia, Institute of Atmospheric Physics, \\ Chinese Academy of Sciences, Beijing, China
}

\section{CHUNZAI WANG}

State Key Laboratory of Tropical Oceanography, South China Sea Institute of Oceanology, and Innovation Academy of South China Sea Ecology and Environmental Engineering, Chinese Academy of Sciences, and Southern Marine Science and Engineering Guangdong Laboratory (Guangzhou) Guangzhou, China

\section{TIANBAO ZHAO}

CAS Key Laboratory of Regional Climate-Environment for Temperate East Asia, Institute of Atmospheric Physics, Chinese Academy of Sciences, Beijing, China

(Manuscript received 3 April 2019, in final form 10 October 2019)

\begin{abstract}
Seasonal covariability of the dryness/wetness in China and global sea surface temperature (SST) is investigated by using the monthly self-calibrated Palmer drought severity index (PDSI) data and other data from 1950 to 2014. The singular value decomposition (SVD) analysis shows two recurring PDSI-SST coupled modes. The first SVD mode of PDSI is associated with the warm phases of the eastern Pacific-type El Niño-Southern Oscillation (ENSO), the interdecadal Pacific oscillation (IPO) or Pacific decadal oscillation (PDO), the Indian Ocean basin mode (IOBM) in the autumn and winter, and the cold phase of the IOBM in the spring. Meanwhile, the Atlantic multidecadal oscillation (AMO) pattern appears in every season except the autumn. The second SVD mode of PDSI is accompanied by a central Pacific-type El Niño developing from the winter to autumn over the tropical Pacific and a positive phase of IPO or PDO from the winter to summer. Moreover, an AMO pattern is observed in all seasons except the summer, whereas the SST over the tropical Indian Ocean shows negligible variations. The further analyses suggest that AMO remote forcing may be a primary factor influencing interdecadal variability of PDSI in China, and interannual to interdecadal variability of PDSI seems to be closely associated with the ENSO-related events. Meanwhile, the IOBM may be a crucial factor in interannual variability of PDSI during its mature phase in the spring. In general, the SST-related dryness/wetness anomalies can be explained by the associated atmospheric circulation changes.
\end{abstract}

\section{Introduction}

China is the most populated nation (Piao et al. 2010) and has one of the fastest-growing economies in the

Denotes content that is immediately available upon publication as open access.

Supplemental information related to this paper is available at the Journals Online website: https://doi.org/10.1175/JCLI-D-190250.s1.

Corresponding author: Dr. Chunzai Wang, cwang@scsio.ac.cn world (Hubacek et al. 2007). While China is experiencing rapid industrialization, urbanization, growing agricultural demand, and environmental degradation, a variety of problems have challenged the management and utilization of China's water resources (Varis and Vakkilainen 2001). Moreover, uneven spatial and seasonal distribution of water resources leads to frequent floods in southern regions of China and results in recurrent water stress in northern China (Zhai et al. 2010). According to the statistics from the latest released Bulletin of Flood and Drought Disaster in China (Ministry of Water Resources of the People's Republic of China 2017), China suffers great economic losses and casualties by 
floods, with an average of 4155 deaths every year during the period 1950-2017. Meanwhile, droughts in China cause the annual loss of grain yield of 16.26 billion $\mathrm{kg}$, accounting for over $60 \%$ of the total crop loss caused by natural disasters, and economic losses of CNY 88.23 billion per year. Therefore, it is of scientific and practical merit to have a thorough analysis of the processes that cause the abnormal conditions of dryness or wetness and to improve our capability to forecast their occurrence.

A number of indices have been used for dryness/ wetness quantification, monitoring, and analysis, each with its unique properties, advantages, and shortcomings (Heim 2002; Vicente-Serrano et al. 2011; Dai 2011a; $\mathrm{Mu}$ et al. 2013). Among these, the Palmer drought severity index (PDSI; Palmer 1965; Alley 1984), which is based on supply and demand in the water balance, is one of the most widely used drought indices in the world (e.g., Zou et al. 2005; Zhang et al. 2017). By combining prior precipitation, moisture supply, runoff, and evaporation demand at the surface level, PDSI is defined to measure of both wetness (positive value) and dryness (negative values). However, there are several limitations in the adoption of PDSI (Alley 1984; Karl 1986; Soulé 1992; Akinremi et al. 1996; Weber and Nkemdirim 1998; Vicente-Serrano et al. 2011), many of which were solved by development of the self-calibrated PDSI (sc-PDSI), a locally standardized index (Wells et al. 2004). Further improvement in PDSI has been obtained with the PenmanMonteith equation (sc_PDSI_pm) by using a more realistic estimate of potential evapotranspiration. It has improved spatial comparability by considering the factors of temperature, high winds, sunlight, humidity, and soil moisture (Dai 2011b). As a result, the sc_PDSI_pm can be more appropriate for research at the national scale (Shabbar and Skinner 2004; Dai 2011b; Zhao and Dai 2015), but few studies have used this index to analyze dryness/wetness variation in China.

Previous studies have compared and highlighted the role of global and regional sea surface temperature (SST) in dryness/wetness in China (e.g., Li et al. 2015; Wang and He 2015). El Niño-Southern Oscillation (ENSO) is supposed to be related to interannual variability of precipitation in China through atmospheric teleconnections (Feng et al. 2011; Wang and Wang 2013; Zhang et al. 2014). The interdecadal Pacific oscillation (IPO; Zhang et al. 1997; Power et al. 1999; Liu 2012; Dai 2013) or Pacific decadal oscillation (PDO; Mantua et al. 1997) is an ENSO-like interdecadal change in the Pacific. The precipitation overall decreases during El Niño/PDO warm phases and increases during La Niña/PDO cool phases in the majority of China (Ouyang et al. 2014). For the Indian Ocean, observational and modeling studies showed that the Indian Ocean basin mode (IOBM) tends to impact the summer precipitation in east China (Yang et al. 2007). Meanwhile, the monsooninduced rainfall over China in the summer is remotely influenced by different phases of the Indian Ocean dipole (IOD) via changes in intensity of the South Asian high and the western North Pacific (WNP) anticyclone (e.g., Li and $\mathrm{Mu}$ 2001; Guan and Yamagata 2003; Qiu et al. 2014). Possible links between SST anomaly (SSTA) patterns in the Indo-Pacific Oceans (El Niño, El Niño Modoki, and the IOD) and the summer rainfall/temperature anomalies in China have also been studied (Weng et al. 2011). Recently, Zhang et al. (2017) classified ENSO, PDO, and the combination of North Pacific current and global warming as drivers of interannual variability, decadalmultidecadal oscillation, and nonlinear trend of the summer PDSI in China, respectively. At regional scale, some studies have shown that wet/dry variations in eastern China are statistically related to PDO (e.g., Ma 2007; Mao et al. 2011; Qian and Zhou 2014), warming in the tropical Pacific and Indian Oceans (e.g., Hu 1997; Zhou et al. 2006; Zhou et al. 2009a; Li et al. 2010), and the Atlantic multidecadal oscillation (AMO; Qian et al. 2014).

The aforementioned studies highlight the importance of investigating and evaluating the role of global SSTA in variability of dryness and wetness in China. Nevertheless, relevant research has been mainly focused on regional scales and/or over regions that became more exposed to severe droughts or floods, such as northern China (Qian and Zhou 2014; Wang and He 2015), eastern China (Qian et al. 2014), and the Yangtze River basin (Xiao et al. 2015). Moreover, the majority of previous studies on the linkage between SSTA and dryness/wetness conditions were carried out in one or two seasons rather than for their seasonal covariability relationship.

Motivated by these mentioned above, the present paper focuses on a comprehensive analysis of the spatiotemporal patterns for the linkage of seasonal dryness/ wetness variability in China and oceanic conditions from 1950 to 2014. The objectives of this study are the following: 1) to document the seasonal leading modes of global SST variability and dryness/wetness variability in China based on the high-accuracy sc_PDSI_pm, 2) to determine the primary climate factors and the role of these factors in modifying the covariability patterns, and 3 ) to identify the possible physical mechanisms of these covariations. The rest of this paper is organized as follows. Section 2 introduces datasets and methods 
used in the study. In section 3, we use a singular value decomposition (SVD) analysis to identify a group of climate variability, consisting of ENSO, IPO, PDO, IOD, IOBM, and AMO, which are important to seasonal variation of dryness/wetness in China. The possible mechanisms are discussed in section 4 . Section 5 examines the relationships between PDSI and climate factors, and section 6 summarizes the results.

\section{Datasets and methods}

The monthly self-calibrated PDSI (Wells et al. 2004) with Penman-Monteith potential evapotranspiration data (sc_PDSI_pm) (Dai 2011b; van der Schrier et al. 2011) are used in the present study to assess dry/wet conditions in China. There is an updated version of these data for the period 1850-2014 (archived online at http://www.cgd.ucar.edu/cas/catalog/climind/ pdsi.html). This combination improves the spatial homogeneity although temporal inhomogeneity may still exist for a small number of grid boxes in northern Africa and other regions, especially for periods before 1950. Therefore, we focus on the period of 1950-2014. The PDSI is a standardized measure, ranging from approximately -10 to +10 and with values below -3 or above +3 representing severe to extreme circumstances. Negative and positive PDSIs indicate dry and wet conditions, respectively.

Gridded precipitation and temperature data come from the Climate Research Unit (CRU) time series (TS) version 3.10 data derived from gauge observations for 1950-2014 with a resolution of $0.5^{\circ} \times 0.5^{\circ}$ (Harris et al. 2014). Additionally, the water vapor flux (WVF) data are provided by ERA-40 for the period 1950-78 (Simmons and Gibson 2000) and ERA-Interim from 1979 onward (Dee et al. 2011). They are available online as an integral over the atmospheric column for the eastward $(u)$ and northward $(v)$ components retrieved from 23 pressure levels between 300 and $1000 \mathrm{hPa}$. SST data are obtained from the monthly mean Hadley Centre Global Sea Ice and Sea Surface Temperature (HadISST) dataset with a spatial resolution of $1^{\circ} \times 1^{\circ}$ (Rayner et al. 2003). Monthly values of the SST-based indices described in Table $\mathrm{S} 1$ in the online supplemental material, including Niño-3, Niño-4, IPO, PDO, dipole mode index (DMI), IOBM, and AMO, are used to represent the strengths of these major interannual and interdecadal modes. From the monthly data, the seasonal means were calculated by averaging the months of January-March (JFM), April-June (AMJ), July-September (JAS), and October-December (OND), which refer to the boreal winter, spring, summer, and autumn, respectively. The time series of the SST indices were normalized by their corresponding standard deviation.

We employ an SVD analysis to identify covariability of spatial associations between SSTA over the global domain $\left(60^{\circ} \mathrm{S}-60^{\circ} \mathrm{N}\right)$ and PDSI anomalies in China for the 65-yr period from 1950 to 2014 . We first detrend the data before the SVD analysis is applied to remove any effect that the trend may have on the results. Briefly, the SVD method decomposes the covariance matrix of these two combined data fields into orthogonal pairs of spatial patterns that maximize the squared temporal covariance between the two variables. The associated squared covariance fraction (SCF) represents the amount of variability each mode in terms of a fraction of total covariability. In addition, the expansion coefficients for either field are matrix products of the field and its loading map. For all seasons, we retained just the first two leading modes, which together explain more than $40 \%$ of the total squared covariance. In the present study, the first (second) expansion coefficient (EC) of SSTA and PDSI field in China are normalized and referred to as EC1_S and EC1_P (EC2_S and EC2_P), respectively. For more details on the SVD method and its application, please refer to Bretherton et al. (1992) and Wallace et al. (1992).

To discover which of these climatic indices (e.g., ENSO, IPO, PDO, IOD, IOBM, and AMO) is the dominant mechanism driving the temporal variation of dryness/wetness, the Pearson correlation coefficients between the first two expansion coefficients of PDSI and the climatic indices have been computed. We also have calculated the pattern correlation between the first two SVD modes of PDSI and the climate index-related pattern of PDSI in order to identify which of the indices is the crucial factor in the spatial variation of the dryness/wetness in China (shown in Table 1). Here, the climate index-related spatial pattern of PDSI is calculated based on the linear regressions of the seasonal PDSI on the climatic index for all the grids in China. To remove the possible asymmetric influence, onesided linear regression analysis is conducted separately for positive or negative climate indices (Ohba and Ueda 2009; Li et al. 2018). For example, if we get a positive (negative) pattern correlation between the SVD mode of PDSI and the AMO-related PDSI, we calculate a linear regression between the AMO index and response variable when the AMO index is positive (negative). Moreover, the regional relationships between PDSI and climatic indices are further examined by the correlations between the climatic indices and area-averaged PDSI anomalies over the selected subregions (Table 2). 
TABLE 1. The Pearson correlation coefficient between the first two expansion coefficients of SSTA (R_EC1_S, R_EC2_S) and PDSI (R_EC1_P, R_EC2_P) and the climate indices, and the pattern correlation between the first two SVD modes of PDSI and the climate index-related pattern of PDSI (Patt_cor1, Patt_cor2). Numbers with asterisks are significant at the 5\% level. The values in bold denote the largest correlation in the season among the indices.

\begin{tabular}{|c|c|c|c|c|c|c|c|}
\hline & & \multicolumn{3}{|c|}{ SVD1 } & \multicolumn{3}{|c|}{ SVD2 } \\
\hline & & R_EC1_S & R_EC1_P & Patt_cor1 & R_EC2_S & R_EC2_P & Patt_cor2 \\
\hline \multirow[t]{7}{*}{ JFM } & Niño-3 & $0.46^{*}$ & $0.86 *$ & $0.92 *$ & $0.27 *$ & $0.63 *$ & $0.4^{*}$ \\
\hline & Niño-4 & $0.44 *$ & $0.79 *$ & $0.93 *$ & 0.12 & $0.56^{*}$ & $0.2^{*}$ \\
\hline & IPO & $0.39 *$ & $0.83^{*}$ & $0.88^{*}$ & $0.31 *$ & $0.74 *$ & $0.54 *$ \\
\hline & PDO & 0.15 & $0.45^{*}$ & $0.67 *$ & $0.35^{*}$ & $0.61 *$ & 0.1 \\
\hline & DMI & -0.08 & -0.17 & -0.02 & -0.1 & $-0.31^{*}$ & $-0.65^{*}$ \\
\hline & IOBM & $0.52 *$ & $0.85 *$ & $0.89 *$ & 0.04 & $0.31 *$ & $0.21 *$ \\
\hline & AMO & $0.36^{*}$ & $0.41 *$ & $0.34 *$ & $-0.46^{*}$ & $-0.46^{*}$ & $-0.84 *$ \\
\hline \multirow[t]{7}{*}{ AMJ } & Niño-3 & 0.04 & $-0.29 *$ & $-0.21 *$ & $0.28 *$ & $0.61 *$ & $0.34 *$ \\
\hline & Niño-4 & -0.24 & $-0.54 *$ & $-0.69 *$ & 0.17 & $0.57 *$ & 0.14 \\
\hline & IPO & -0.06 & $-0.43^{*}$ & $-0.44^{*}$ & $0.4^{*}$ & $0.83^{*}$ & $0.55^{*}$ \\
\hline & PDO & -0.14 & $-0.39 *$ & $-0.49 *$ & $0.34 *$ & $0.64 *$ & $0.27 *$ \\
\hline & DMI & 0.22 & 0.13 & 0.07 & 0.22 & 0.13 & 0.03 \\
\hline & IOBM & $-0.34 *$ & $-0.73 *$ & $-0.78^{*}$ & 0.16 & $0.4 *$ & $0.45^{*}$ \\
\hline & AMO & $-0.54 *$ & $-0.67^{*}$ & $-0.78^{*}$ & $-0.31^{*}$ & -0.15 & $-0.39 *$ \\
\hline \multirow[t]{7}{*}{ JAS } & Niño-3 & 0.15 & $0.31 *$ & -0.03 & $0.31 *$ & $0.67 *$ & $0.39 *$ \\
\hline & Niño-4 & 0.03 & 0.19 & $-0.38^{*}$ & $0.44 *$ & $0.79 *$ & $0.55^{*}$ \\
\hline & IPO & 0.15 & $0.39 *$ & 0.12 & $0.46^{*}$ & $0.88 *$ & 0.79* \\
\hline & PDO & 0.11 & $0.34 *$ & $0.3^{*}$ & $0.32 *$ & $0.67 *$ & $0.75^{*}$ \\
\hline & DMI & 0.17 & 0.22 & $-0.17 *$ & 0.14 & $0.28 *$ & $0.18^{*}$ \\
\hline & IOBM & -0.12 & -0.18 & $-0.35^{*}$ & 0.17 & $0.32 *$ & $0.27 *$ \\
\hline & AMO & $-0.54 *$ & $-0.77 *$ & $-0.82^{*}$ & 0.12 & 0.12 & $0.21 *$ \\
\hline \multirow[t]{7}{*}{ OND } & Niño-3 & $0.58^{*}$ & $0.91 *$ & $0.88^{*}$ & 0.02 & 0.11 & $0.38^{*}$ \\
\hline & Niño-4 & $0.45^{*}$ & $0.85^{*}$ & $0.61 *$ & $0.27 *$ & $0.24 *$ & $0.67 *$ \\
\hline & IPO & 0.58* & $0.97 *$ & 0.92* & 0.04 & 0.08 & $0.38^{*}$ \\
\hline & PDO & $0.41 *$ & $0.65^{*}$ & $0.71 *$ & 0 & -0.11 & $0.37 *$ \\
\hline & DMI & $0.28^{*}$ & $0.46^{*}$ & $0.45^{*}$ & -0.06 & 0.13 & $0.32 *$ \\
\hline & IOBM & $0.39 *$ & $0.57 *$ & $0.61 *$ & 0.13 & $0.32 *$ & $0.51 *$ \\
\hline & $\mathrm{AMO}$ & -0.15 & -0.18 & $-0.34^{*}$ & $0.61 *$ & $0.89 *$ & $0.85^{*}$ \\
\hline
\end{tabular}

\section{Relationship with global SSTA}

\section{a. First SVD: The developing eastern Pacific-type ENSO mode}

The loading vectors for the first leading mode, which accounts for $25.8 \%-34.3 \%$ of the squared covariance between the two fields, are shown in Fig. 1. The time series of the corresponding expansion coefficients, shown in Fig. 2, are highly correlated with one another in all seasons [correlation coefficient $(r)$ greater than 0.66]. This suggests a tight coupling between the SSTA and dryness/wetness conditions. From the spring (AMJ) to winter (JFM), the SST mode of variability over the tropical Pacific displays a warm anomaly extending from the eastern Pacific to the central Pacific, representing the development of the traditional El Niño structure. Over the extratropical Pacific, SSTA is characterized by an ENSO-like spatial pattern in OND and JFM. For the Indian Ocean, a positive IOBM phase occurs in the autumn (Fig. 1e) and winter (Fig. 1g), whereas a negative IOBM appears in the spring (Fig. 1a). This result is in line with previous studies, which proposed that the El Niñoinduced IOBM (Stuecker et al. 2015; Zhang et al. 2015) usually starts to develop during the El Niño autumn season and persists into the boreal summer of the following calendar year (e.g., Stuecker et al. 2015). In the Atlantic Ocean, a negative AMO pattern is found during the spring (Fig. 1a) and summer (Fig. 1c), but a positive AMO is observed in the winter (Fig. 1g).

Correspondingly, the EC1_S time series presents a strong interannual-interdecadal variability component in AMJ and JAS, which can be inferred from the time evolution of the spring and summer EC1_S time series (Figs. 2a,b). It is negatively correlated with the AMO index, confirming that the SST pattern is associated with the cold phase of AMO in AMJ and JAS $(r=-0.54$, 99\% confidence level; Table 1). During OND, the EC1_S time series is characterized by a pronounced interannual variability and positively correlated with all the indices except the AMO $(r=0.58,0.45,0.58$, $0.41,0.28,0.39$, and -0.15 for the Niño-3, Niño- 4 , IPO, PDO, DMI, IOBM, and AMO indices, respectively). 
TABLE 2. Correlation coefficients between the climate indices and the area-averaged PDSI anomalies in southeastern China (SE), eastern China (EC), northern China (NC), northeastern China (NE), northwestern China (NW), and southwestern China (SW), respectively. Shown are January-March (JFM), April-June (AMJ), July-September (JAS), and October-December (OND). Numbers with asterisks are significant at the $5 \%$ level. The values in bold denote the largest correlation in the season over the subregion among the indices.

\begin{tabular}{|c|c|c|c|c|c|c|c|}
\hline & & \multicolumn{6}{|c|}{ Subregions } \\
\hline & & SE & EC & $\mathrm{NC}$ & $\mathrm{NE}$ & NW & SW \\
\hline \multirow[t]{7}{*}{ JFM } & Niño-3 & $0.44 *$ & 0.14 & -0.23 & -0.1 & 0.09 & -0.04 \\
\hline & Niño-4 & $0.32 *$ & 0.09 & -0.13 & -0.03 & 0.15 & -0.12 \\
\hline & IPO & $0.39 *$ & 0.10 & -0.21 & -0.09 & 0.03 & -0.03 \\
\hline & $\mathrm{PDO}$ & 0.08 & -0.13 & $-0.43 *$ & -0.23 & 0.12 & -0.20 \\
\hline & DMI & -0.24 & $-0.26^{*}$ & -0.06 & -0.07 & 0.06 & $-0.28 *$ \\
\hline & IOBM & $0.35 *$ & 0.16 & -0.02 & 0.11 & 0.10 & -0.15 \\
\hline & AMO & -0.12 & -0.05 & -0.01 & 0.2 & $0.33 *$ & $-0.36 *$ \\
\hline \multirow[t]{7}{*}{ AMJ } & Niño-3 & 0.05 & -0.14 & -0.17 & -0.23 & 0.07 & -0.14 \\
\hline & Niño-4 & 0.05 & -0.05 & -0.11 & -0.13 & $0.27 *$ & -0.23 \\
\hline & IPO & 0.13 & -0.13 & -0.18 & -0.22 & 0.12 & -0.15 \\
\hline & PDO & 0.12 & -0.22 & $-0.28 *$ & -0.13 & 0.27 & -0.16 \\
\hline & DMI & -0.03 & -0.16 & $-0.38 *$ & $-0.38 *$ & 0.09 & -0.04 \\
\hline & IOBM & 0.17 & 0.22 & 0.11 & 0.03 & 0.15 & -0.15 \\
\hline & AMO & -0.13 & -0.01 & -0.09 & 0.21 & 0.44* & $-0.49 *$ \\
\hline \multirow[t]{7}{*}{ JAS } & Niño-3 & -0.05 & -0.12 & $-0.29 *$ & -0.07 & -0.05 & -0.14 \\
\hline & Niño-4 & -0.1 & $-0.31 *$ & $-0.33^{*}$ & -0.07 & 0.11 & -0.19 \\
\hline & IPO & -0.01 & -0.15 & $-0.26^{*}$ & -0.05 & -0.01 & -0.08 \\
\hline & PDO & 0.03 & -0.01 & -0.14 & -0.06 & 0.11 & 0.04 \\
\hline & DMI & -0.08 & $-0.30 *$ & $-0.38 *$ & -0.22 & 0.09 & $-0.26^{*}$ \\
\hline & IOBM & -0.03 & -0.05 & -0.19 & 0.04 & 0.16 & -0.02 \\
\hline & AMO & -0.19 & 0.05 & -0.18 & 0.13 & $0.40 *$ & $-0.42 *$ \\
\hline \multirow[t]{7}{*}{ OND } & Niño-3 & $0.33 *$ & 0.01 & $-0.36^{*}$ & 0 & 0.02 & -0.18 \\
\hline & Niño-4 & 0.08 & -0.11 & $-0.35^{*}$ & 0 & 0.16 & $-0.27 *$ \\
\hline & IPO & 0.24 & -0.02 & $-0.34^{*}$ & 0.03 & 0.01 & -0.15 \\
\hline & PDO & 0.04 & 0.02 & $-0.26^{*}$ & -0.03 & 0.09 & $-0.26^{*}$ \\
\hline & DMI & $0.33 *$ & -0.04 & $-0.26^{*}$ & -0.14 & 0.17 & -0.18 \\
\hline & IOBM & 0.24 & -0.05 & -0.21 & 0.02 & 0.08 & -0.15 \\
\hline & AMO & -0.21 & -0.15 & 0 & 0.23 & 0.39* & $-0.37 *$ \\
\hline
\end{tabular}

During JFM, the positive correlations are observed between EC1_S and the Niño-3, Niño-4, IOBM, AMO, and IPO indices. These results suggest that positive values of EC1_S are associated with the warm phases of ENSO, IOBM, and IPO in the fall and are persistent to the winter.

Following the SSTA patterns, there is a dipole-like pattern of PDSI between southwestern China and the rest of China in AMJ. The enhanced moisture during the positive episodes of the EC1_P time series, indicated by the positive loading, is centered over southwestern China. Meanwhile, the decreased moisture, denoted by the negative loading, occurs over northwestern, northeastern, and southeastern China (Fig. 1b). The drier condition retreats from the northern parts of China to the central parts of China, while the wetter condition shifts eastward from southwestern to southeastern China as the season progresses from the spring to winter (Figs. 1b,d,f,h). In addition, we regressed the seasonal EC_P1 against the contemporaneous SSTAs and the EC_S1 against the PDSI anomalies (not shown). It is found that the corresponding regression patterns resemble the seasonal evolution identified in the SVD analysis, reconfirming that the ENSO, IPO/PDO, IOD/IOBM, and AMO patterns of SST anomalies in the global oceans are closely associated with and may be important to PDSI variability in China.

Similar to the case of EC1_S, the EC1_P time series emphasizes both interannual and interdecadal variability in AMJ and JAS but interannual variability in OND and JFM (Fig. 2). For all the seasons, the EC1_P time series is significantly correlated with the Niño-3, IPO, and PDO indices (Table 1), indicating a persistent influence of Pacific SSTA on the dryness/wetness variability in China. During JAS (OND), the correlation between EC1_P and DMI/IOBM (AMO) is insignificant, implying an absence of IOD/IOBM (AMO) influence.

By comparing the temporal correlation and pattern correlation, the relative importance of each of these climatic indices in affecting covariability is assessed. From the spring to winter, both the largest temporal correlation between the time series of EC1_S and the 
(a) AMJ

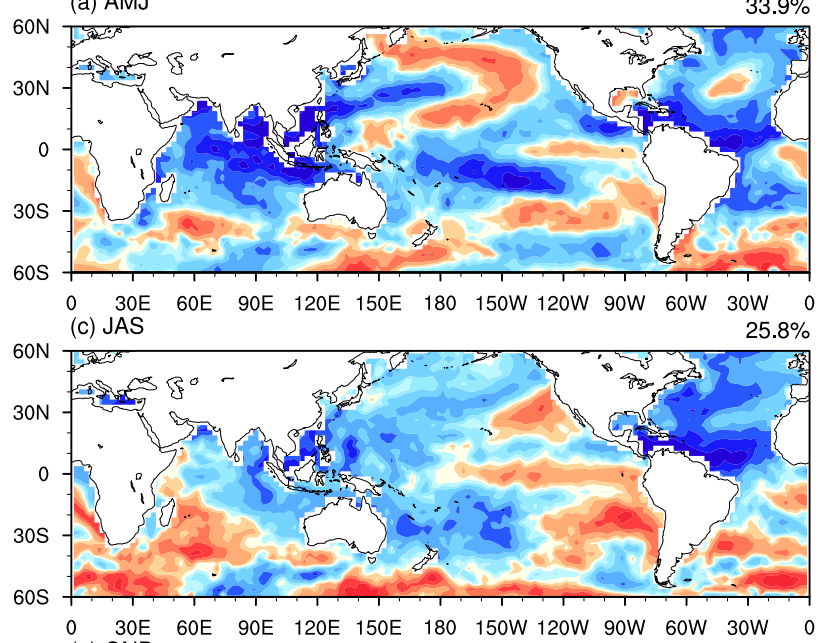

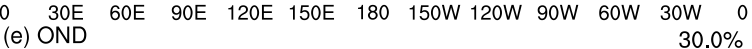
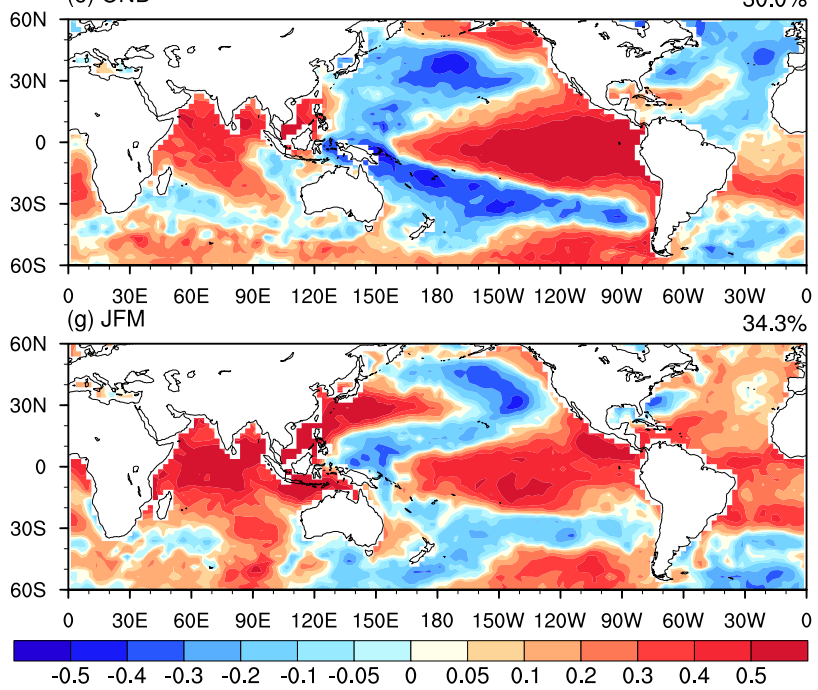

(b) AMJ
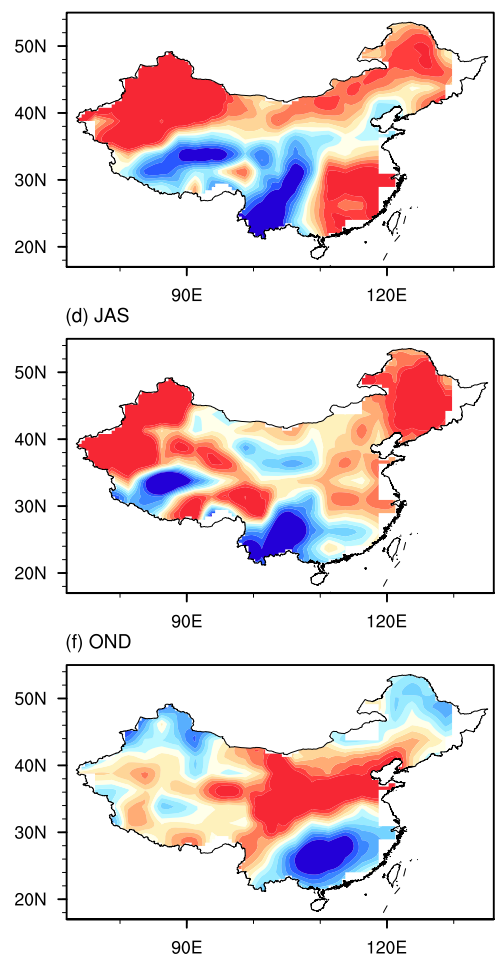

(h) JFM

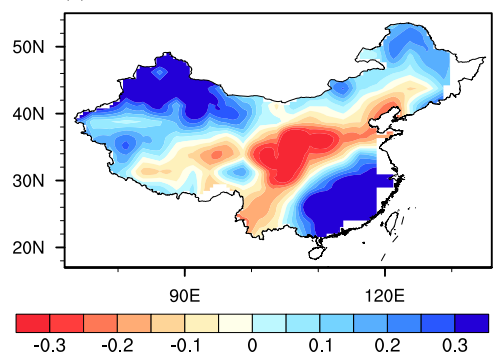

FIG. 1. The first SVD modes of the seasonal detrended SST and PDSI anomalies, showing the spatial patterns of (left) SST and (right) PDSI for the season mean during (a),(b) AMJ, (c),(d) JAS, (e),(f) OND, and (g), (h) JFM. The squared covariance fraction is provided at the top right of the left column for each mode.

climatic indices and the largest pattern correlation between the first SVD modes of PDSI and the indexrelated pattern of PDSI are found in IOBM, AMO, IPO, and Niño-3/Niño-4, respectively (Table 1). These results imply that the AMO remote forcing may be a primary factor influencing PDSI variability in China during the summer, while IPO may be a crucial factor for PDSI during the autumn. In the mature phase of ENSO (winter) and IOBM modes (spring), PDSI variability seems to be closely associated with ENSO and IOBM events, respectively.

\section{b. Second SVD: The developing central Pacific-type ENSO mode}

The second mode of SVD explains more than $15.9 \%$ of the total variance. For the SST mode (left column of
Fig. 3), a central Pacific-type El Niño develops from the winter (JFM) to autumn (OND) over the tropical Pacific. In the extratropical Pacific, there is a positive phase of IPO or PDO from the winter to summer. Furthermore, an AMO pattern is found in all seasons except JAS. However, the SST over the tropical Indian Ocean shows negligible loadings, indicating that neither IOD nor IOBM can be discerned during the entire year. It is consistent with the seasonal SST variations over the tropical Indian Ocean for a central Pacific-type El Niño displayed in Yuan and Yang (2012).

During OND and JFM, the corresponding EC (EC2_S) time series are characterized by a strong interdecadal variability (Fig. 4). In these two seasons, they are significantly correlated with the AMO index $(r=0.61$ and -0.46 , respectively), as well with PDO, IPO, and 

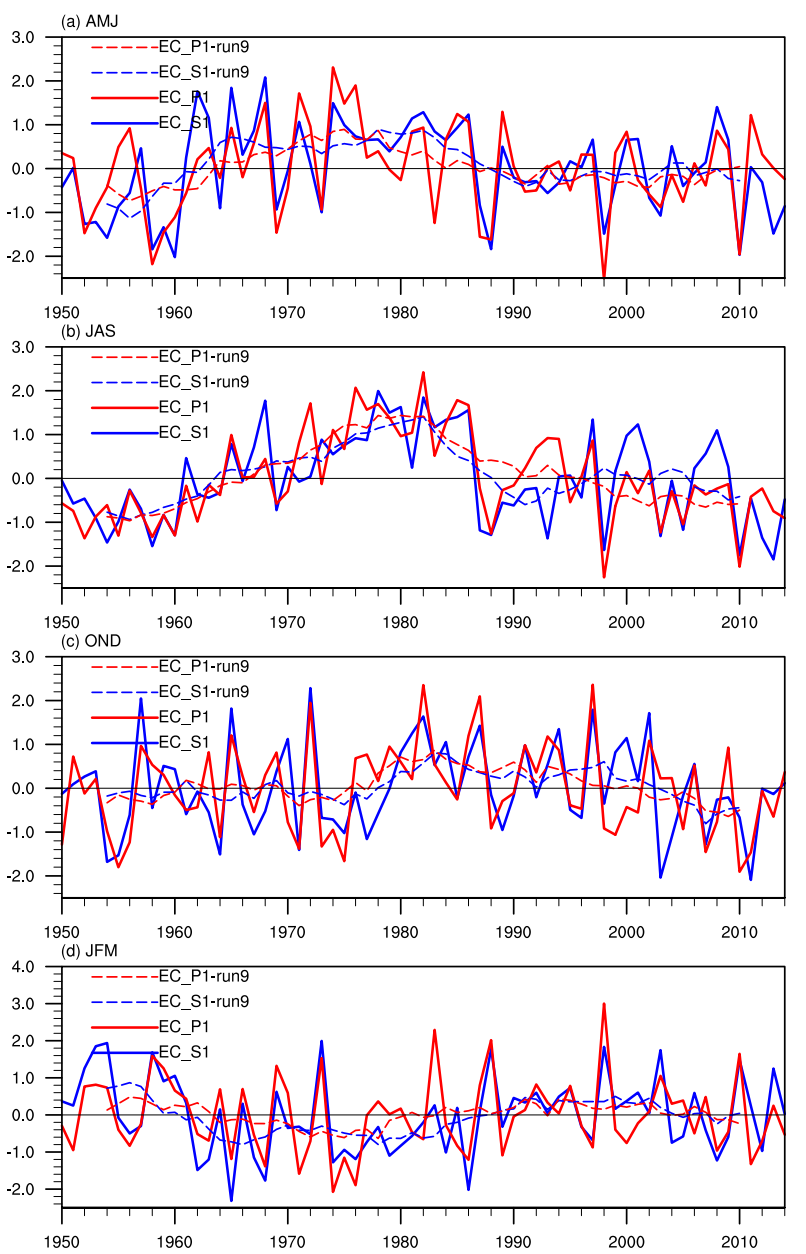

FIG. 2. Time series of expansion coefficients of SSTA (EC_S1; solid blue line) and PDSI (EC_P1; solid red line) of the first SVD mode and their 9-yr running mean (dashed lines) during (a) AMJ, (b) JAS, (c) OND, and (d) JFM.

Niño-3 during JFM ( $r \geq 0.27)$. During AMJ and JAS, EC2_S time series present both interannual and interdecadal variability. They are negatively correlated with the AMO in AMJ $(r=-0.31)$ and positively correlated with the IPO, PDO, Niño-4, and Niño-3 indices in both AMJ and JAS $(r \geq 0.27)$. In all seasons, the correlation between EC2_S and DMI/IOBM is insignificant, reconfirming that tropical Indian Ocean SST shows a negligible impact on the corresponding evolution of PDSI in China.

The spatial pattern associated with the second PDSI mode features a south-north seesaw pattern during the winter (Fig. 3b). Northeastern China, southwestern China, most parts of northern China, and the eastern Tibetan Plateau (TP) become drier in JFM. By contrast, there is a moisture surplus in the rest of China, especially in southern China and the southwestern TP. As the season progresses from the winter to autumn, the drier conditions retreat southwestward. That is, the negative PDSI loadings display a southwest-northeast orientation in AMJ (Fig. 3d) and a zonal band stretching from the western TP northeastward to the southern part of northeastern China in JAS (Fig. 3f). They dominate southwestern China, the western TP, and some regions in central China in OND (Fig. 3h). Correspondingly, increased moisture occurs in the northern parts of northwestern China during AMJ and extends to the entirety of northern China in OND. In contrast, the wetter conditions over southern China weaken from JFM and almost dissipate in OND. Additionally, we regressed the seasonal EC_P2 against the contemporaneous SSTA and the EC_S2 against the PDSI anomalies (not shown). The obtained regression patterns and the evolutions can reproduce the features revealed by the SVD analysis, further confirming the conclusion.

The associated time series of PDSI (EC2_P) are significantly correlated to all the indices in JFM, suggesting that there are close teleconnections between the winter SSTA and PDSI anomalies in China. During AMJ and JAS, the correlations between the EC2_P time series and the AMO is insignificant, indicating an insignificant influence of the AMO on the corresponding PDSI variability in the spring and summer seasons. In addition, the EC2_P time series is highly correlated with the AMO and IOBM in the autumn and winter seasons.

In the spring and summer seasons, both the largest temporal correlation between the time series of ECs and the climatic indices and the largest pattern correlation between the second SVD modes of PDSI and the indexrelated pattern of PDSI are observed in IPO, whereas they are found in the AMO and IPO/AMO in the autumn and winter seasons, respectively (Table 1). We can argue that the ENSO-related variability of SSTA in the Pacific dominates the corresponding PDSI patterns in the spring and summer seasons. It is consistent with the findings that interdecadal variations in the summer or early summer over China, including Northwest China (Zhou and Huang 2009) and South China (Chan and Zhou 2005), are related to ENSO and the IPO/PDO. Nevertheless, the AMO has played a critical role in producing the PDSI variability shown in the SVD2 mode during the autumn and winter seasons.

\section{c. Regional relationship between PDSI variations and climate factors}

To further analyze the regional relationships between the PDSI variations in China and climate indices, we define the following area-averaged PDSI indices to represent the PDSI variability in different subregions (Fig. S1): southeastern China (SE; $20^{\circ}-27.5^{\circ} \mathrm{N}$, 
(a) JFM

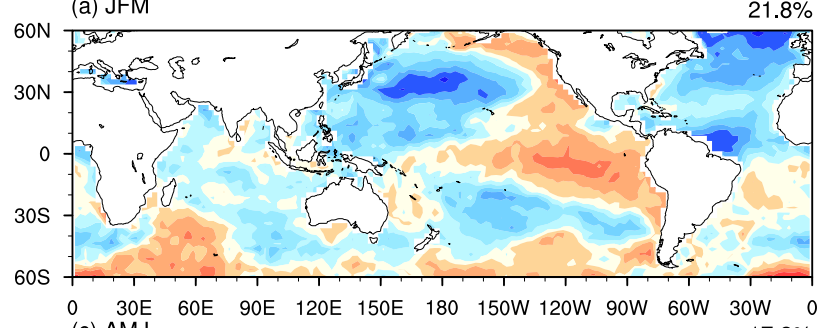

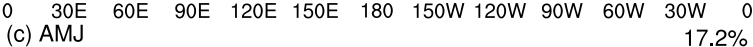
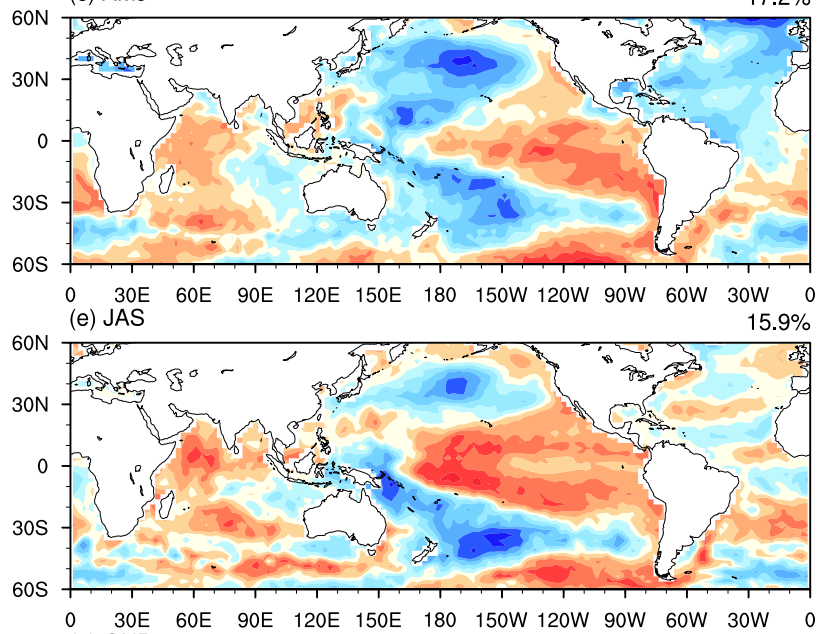

(g) OND $60 \mathrm{E} \quad 90 \mathrm{E} \quad 120 \mathrm{E} \quad 150 \mathrm{E} \quad 180$ 150W $120 \mathrm{~W}$ 90W $60 \mathrm{~W}$ 30W

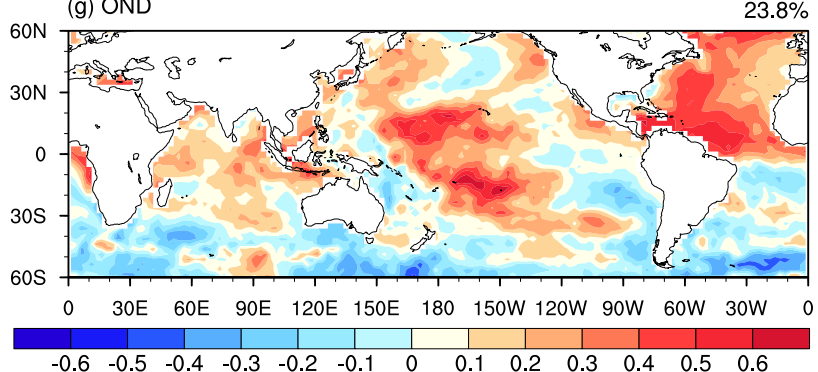

(b) JFM

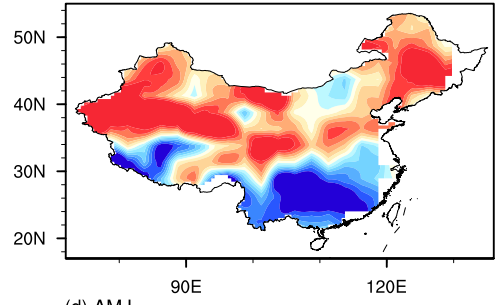

(d) AMJ
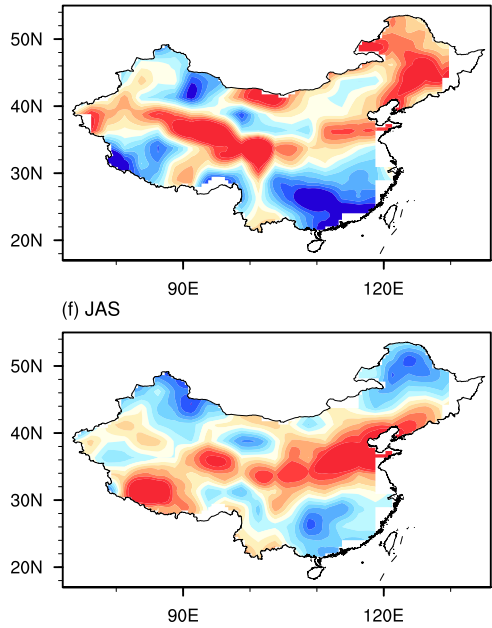

(h) OND

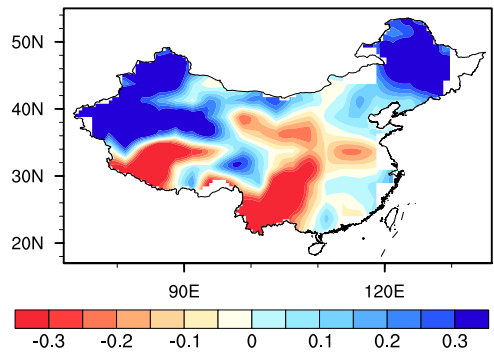

FIG. 3. The second SVD modes of the seasonal detrended SST and PDSI anomalies, showing the spatial patterns of (left) SST and (right) PDSI for the season mean during (a),(b) JFM, (c),(d) AMJ, (e),(f) JAS, and (g),(h) OND. The squared covariance fraction is provided at the top right of left column for each mode.

$\left.105^{\circ}-120^{\circ} \mathrm{E}\right)$; eastern China $\left(\mathrm{EC} ; 27.5^{\circ}-35^{\circ} \mathrm{N}, 110^{\circ}-\right.$ $\left.120^{\circ} \mathrm{E}\right)$; northern China $\left(\mathrm{NC} ; 35^{\circ}-42.5^{\circ} \mathrm{N}, 100^{\circ}-117.5^{\circ} \mathrm{E}\right)$; northeastern China (NE; $\left.42.5^{\circ}-53^{\circ} \mathrm{N}, 117.5^{\circ}-135^{\circ} \mathrm{E}\right)$; northwestern China $\left(\mathrm{NW} ; 37.5^{\circ}-45^{\circ} \mathrm{N}, 75^{\circ}-95^{\circ} \mathrm{E}\right)$; and southwestern China $\left(\mathrm{SW} ; 20^{\circ}-30^{\circ} \mathrm{N}, 95^{\circ}-105^{\circ} \mathrm{E}\right)$.

The correlations between the climate indices and areaaveraged PDSI indices in different seasons (Table 2) share many features with those in the SVD analysis, providing additional confirmation that the seasonal variations of PDSI in China are related to transitions of global SSTA. For instance, there is a significant positive (negative) correlation between the PDSI changes in SE (NC) and the Niño-3 index in OND and JFM (JAS and OND). It indicates that in eastern Pacific El Niño years, an anomalous wet (dry) condition can be found in SE (NC) during the autumn and winter (summer and autumn), which is also mentioned in previous studies (e.g., Wang et al. 2000; Zhang et al. 2011). Meanwhile, the significant negative correlation between the Niño- 4 and PDSI occurs mainly over SE and $\mathrm{NC}$ in the summer, but shifts to SW and NC in the autumn, consistent with the southwestward retreatment of drier conditions associated with the development of central Pacific El Niño mode (Fig. 3). Furthermore, the phase of PDO or IPO is inversely correlated with the PDSI changes over $\mathrm{NC}$ in all seasons, implying decreased (increased) moisture there during the warm (cold) phases of PDO/IPO (Ma 2007; Qian et al. 2014). The PDSI over NW (SW) is positively (negatively) correlated to the AMO in the four seasons, characterizing a seesaw pattern in the PDSI anomalies in the western portion of China associated with the AMO phases. Previous results have shown that 

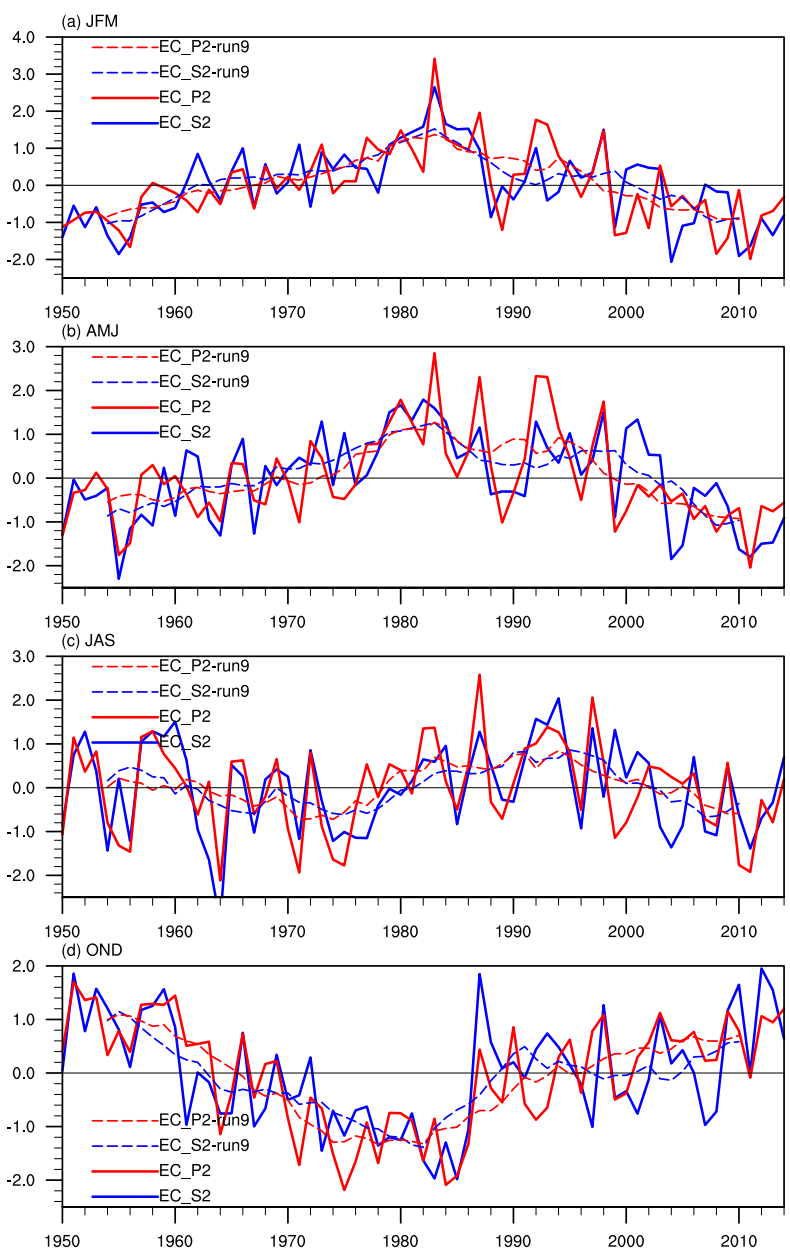

FIG. 4. Time series of expansion coefficients of SSTA (EC_S2; solid blue line) and PDSI (EC_P2; solid red line) of the second SVD mode and their 9-yr running mean (dashed lines) during (a) JFM, (b) AMJ, (c) JAS, and (d) OND.

the AMO is the primary factor influencing the first SVD modes of PDSI in China during AMJ and JAS, whereas the second SVD modes of PDSI are mainly attributed to the AMO during OND and JFM. As expected, anomalous dry (wet) conditions can be found over NW in China during AMJ (Fig. 1a), JAS (Fig. 1c), and JFM (Fig. 3a) associated with the negative AMO phase, and an opposite pattern occurs during the positive AMO phase.

\section{Relationship with large-scale atmospheric circulation, precipitation, and temperature}

To elucidate the general mechanisms responsible for the teleconnection between PDSI seasonal variability and global SST, we examine the changes of the largescale atmospheric circulation, precipitation, and temperature associated with PDSI variability in this section.
We regress the seasonal SST SVD expansion coefficient time series derived from the contemporaneous PDSI anomalies over China against precipitation, the vertical integral of the WVF, and its divergence, temperature, and geopotential height at $500 \mathrm{hPa}$ (Z500).

\section{a. First $S V D$}

Associated with the positive phases of EC1_S time series, the regression maps show that the anomalous easterly or northeasterly water vapor transport dominates most parts of China in the spring because of the anomalous cyclonic moisture circulation over the northeastern Philippine Sea (Fig. 5a). It leads to divergence of moisture and deficient precipitation over most parts of eastern China but convergence of moisture and surplus precipitation over southern China (Figs. 5a,b). Meanwhile, the anomalous anticyclonic moisture circulation appears over northern Northwest China and Russia during the spring (Fig. 5a), resulting in the strengthening of descending flow, increase of temperature (Fig. 6a), divergence of moisture (Fig. 5a), and decrease of precipitation (Fig. 5b) over northwestern and northeastern China. Increased evaporation due to warmer surface temperatures and decreased precipitation will drive significant reductions in wetness across the region (Fig. 1b). In contrast, cyclonic moisture circulation dominates over the eastern Tibetan Plateau, contributing to the strengthening of ascending flow, decrease of temperature, convergence of moisture, and increase of rainfall over southwestern China. The decrease in temperature collocated with enhanced precipitation in southwestern China leads to wet conditions there (Fig. 1b).

During the summer, the aforementioned anomalous cyclone of moisture over the northeast Philippine Sea shifts to the south Sea of Japan, as the south part of the meridional wavelike pattern of the anomalous WVF (Fig. 5c), which is similar to that of the negative phase of East Asian-Pacific/Pacific-Japan (EAP/PJ) pattern (Nitta 1987; Huang 1992). It indicates a reduced dominant mode of the East Asian summer monsoon (EASM). Correspondingly, an out-of-phase pattern of precipitation anomalies is observed over eastern China between southeastern China and the remaining regions to its north, which is consistent with the ENSO-related summer precipitation pattern shown in previous studies (Ahn and Lee 2002; Li et al. 2014). Meanwhile, the anomalous moisture divergence over southwestern China suppresses precipitation there (Fig. 5d). Although the Z500 variability is relatively small, the temperature is significantly reduced over most regions of China (Fig. 6b). When the regression patterns of precipitation (Fig. 5d) and temperature (Fig. 6b) are examined, we can argue that 
(a) AMJ

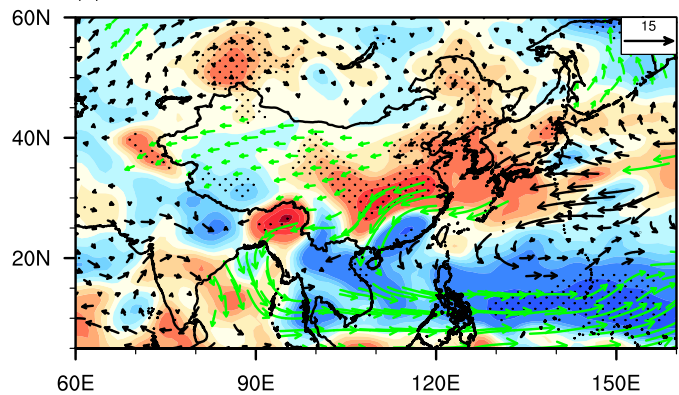

(c) JAS

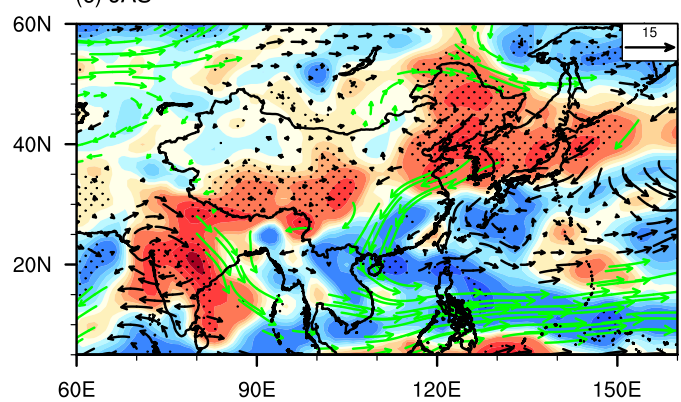

(e) OND

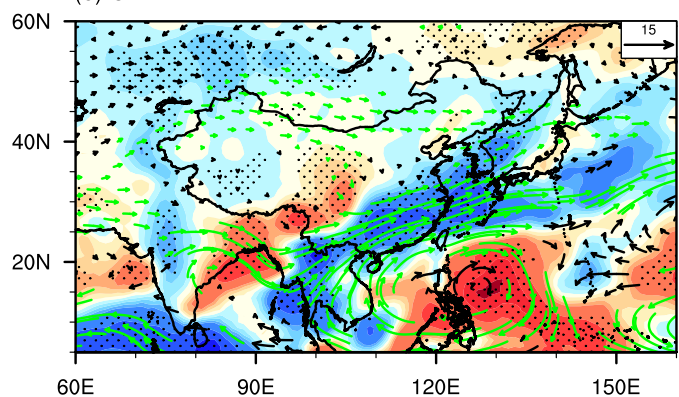

(g) JFM

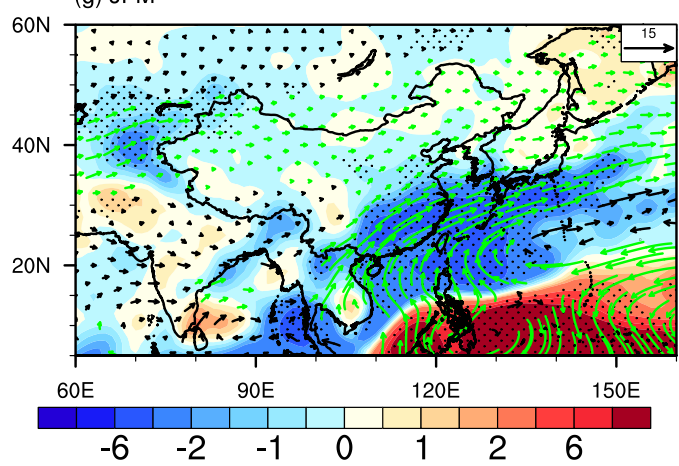

(b) AMJ

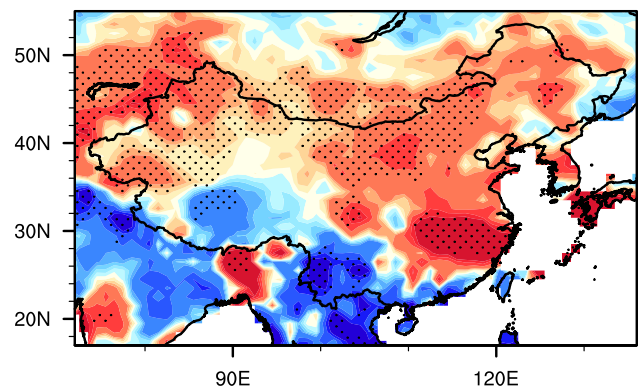

(d) JAS

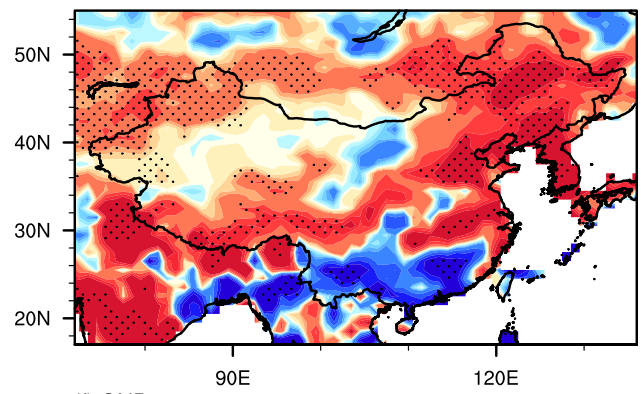

(f) OND

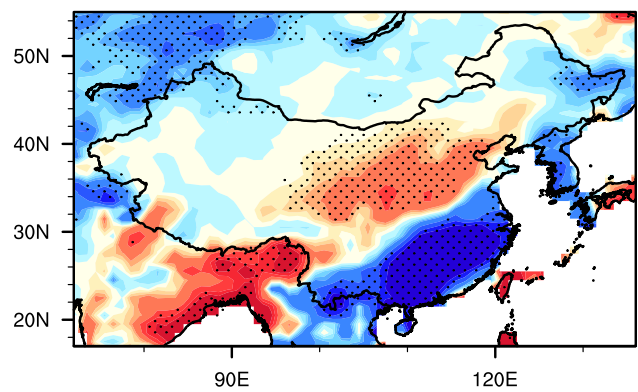

(h) JFM

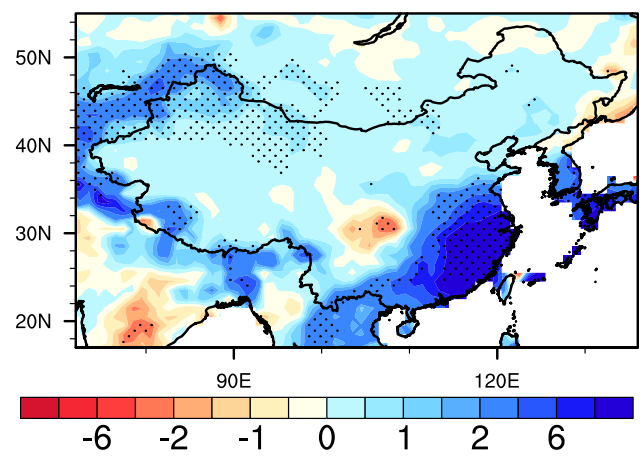

FIG. 5. The EC_S1 time series regressed against (left) the vertically integrated (1000-300 hPa) water vapor flux (vectors; $\mathrm{kg} \mathrm{m}^{-1} \mathrm{~s}^{-1}$ ) and its divergence (shading; $10^{-6} \mathrm{~kg} \mathrm{~m}^{-2} \mathrm{~s}^{-1}$ ) and (right) the precipitation (mm month ${ }^{-1}$ ) for (a),(b) AMJ, (c),(d) JAS, (e),(f) OND, and (g),(h) JFM. All units are per unit standard deviation of the expansion coefficient. The dotted areas and green arrows indicate that the regressions are significant at the $95 \%$ confidence level on the Student's $t$ test.

the precipitation is the main factor driving the summer dry/wet conditions over most of the China region.

Afterward, an anomalous low-level anticyclone located over the Philippine Sea [the Philippine Sea anticyclone (PSAC)] develops in the autumn and is maintained in the winter, in accordance with the previous findings that the anomalous PSAC forms in the fall approximately one season prior to the peak El Niño and persists to the ensuing summer (Wang et al. 1999; Wang and Zhang 2002). It tends to transport more warm and 
(a) AMJ

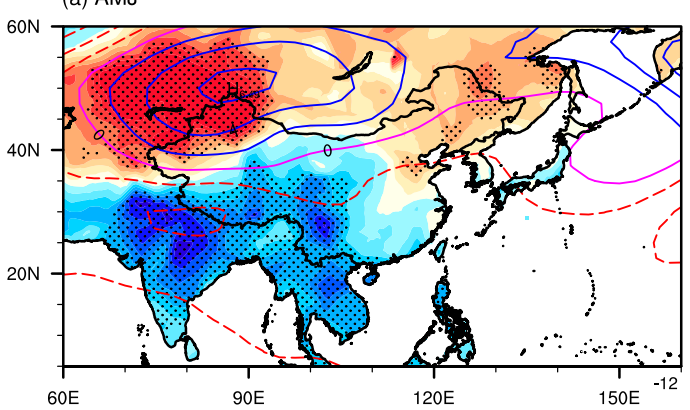

(c) OND
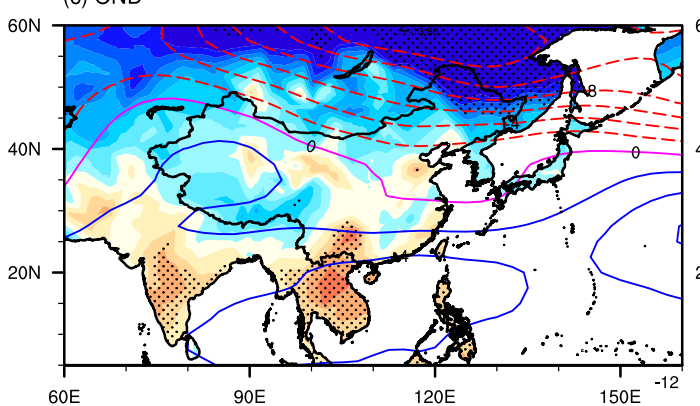

(b) JAS

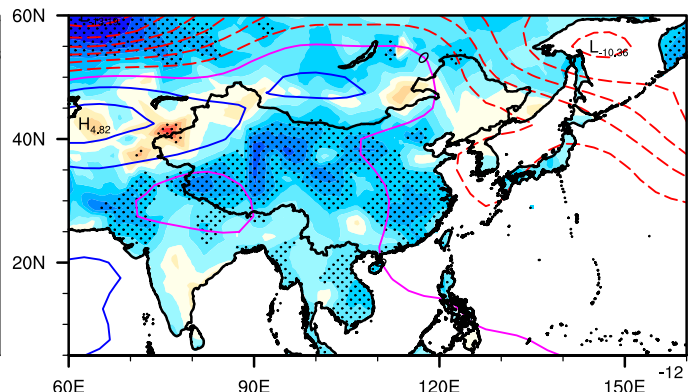

(d) JFM

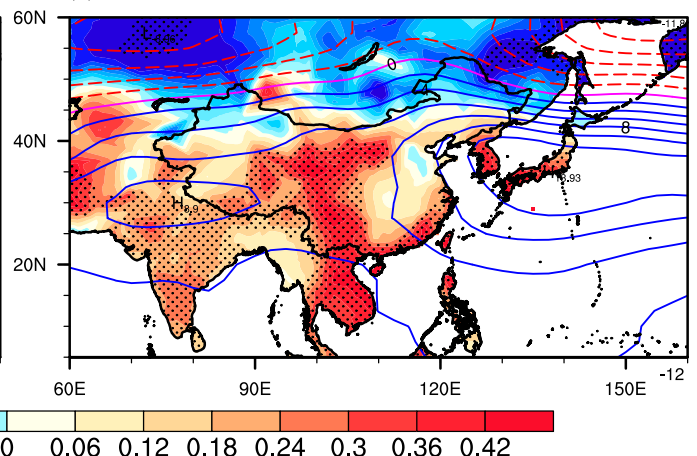

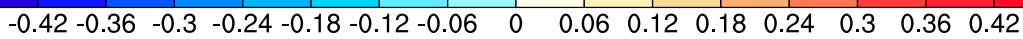

FIG. 6. The EC_S1 time series regressed against of temperature (shading; ${ }^{\circ} \mathrm{C}$ ) and geopotential height at $500 \mathrm{hPa}$ (Z500; contour; gpm) for (a) AMJ, (b) JAS, (c) OND, and (d) JFM. All units are per unit standard deviation of the expansion coefficient. The dotted areas indicate that the regressions of temperature are significant at the $95 \%$ confidence level of the Student's $t$ test. The solid and dashed lines indicate positive and negative values of Z500, respectively.

moist water vapor toward southeastern China and cause a wetter-than-normal climate there, which is also mentioned in previous studies (e.g., Wu et al. 2003; Wang and Wang 2013). Meanwhile, the East Asian trough (EAT) is strengthened by the negative pressure anomalies over the East Asia-Japan-North Pacific region (Fig. 6c). Consistent with the height anomalies, the WVF shows northwesterly advection of cold and dry air over North China (Fig. 5e), which would cause below-normal precipitation there (Fig. 5f). It agrees with the autumn precipitation variations over North China and atmospheric circulation changes associated with IPO/PDO-induced SST variations shown in previous studies (Qin et al. 2018). Associated with insignificant correlation in temperature over most regions of China, the precipitation pattern contributes to the out-of-phase relationship of autumn dryness/wetness condition between North China and Southeast China (Fig. 1f).

During JFM, the aforementioned PSAC intensifies while significant anomalous southwesterlies occur along the east coast of China, indicating a stronger than normal retreat of the East Asian winter monsoon. The outflows of the PSAC and the monsoonal northeasterlies converge over southeastern China, inducing enhancement of precipitation (Fig. 5h) and wetness there (Fig. 1h). Furthermore, a weakened Siberian high contributes to dominant positive temperature anomalies across China, except for the northeast and far northwest. It indicates that precipitation anomalies tend to dominate changes in PDSI in southeastern China during the cold season due to the inherent evaporation minimum during this season. Meanwhile, northwestern China becomes wetter with the anomalous moisture convergence. These results have been partly supported by some previous studies, which pointed out that ENSO-like SSTA and the AMO could induce a weakened Siberian high, produce a strong anomalous anticyclone over the Philippine Sea, and enhance precipitation and temperature over East Asia (Li 1990; Chen et al. 2000; Kim et al. 2014; Hao and He 2017).

\section{b. Second SVD}

Accompanying the anomalous anticyclonic moisture circulation pattern over the south of the South China Sea (SCS), the southwesterly anomalies prevail over the southern parts of China in the winter (Fig. 7a), contributing to enhanced water vapor transport and precipitation over these regions (Fig. 7b). Furthermore, associated with the negative phase of the AMO, the 
(a) JFM

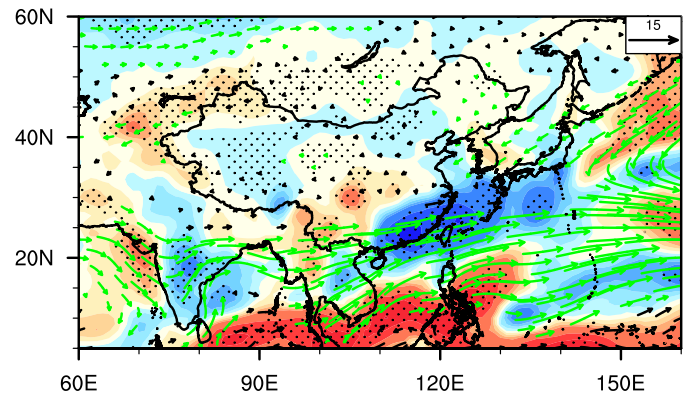

(c) AMJ

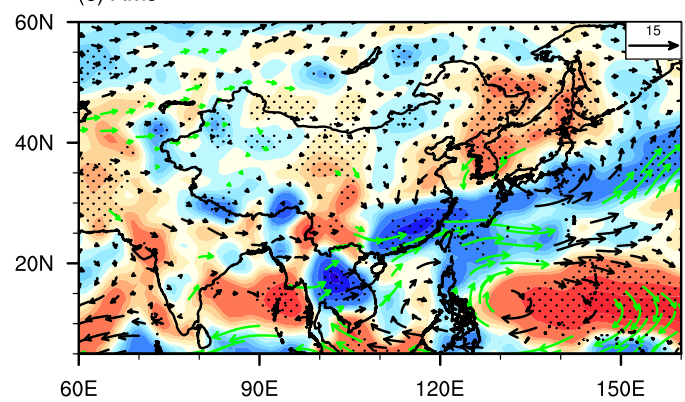

(e) JAS

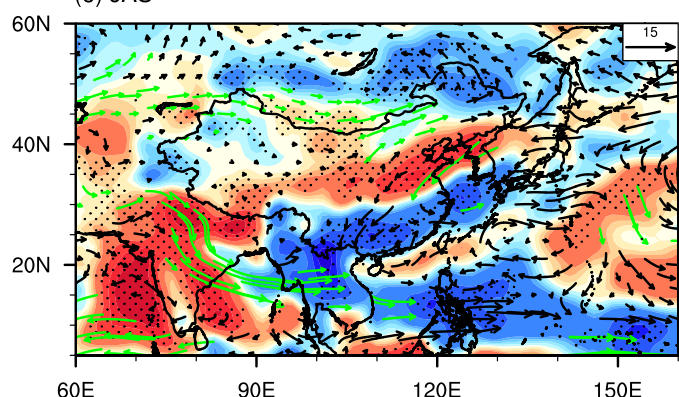

(g) OND

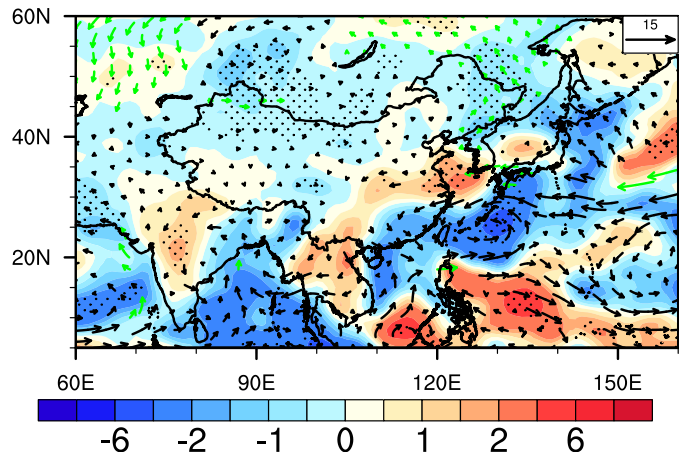

(b) JFM

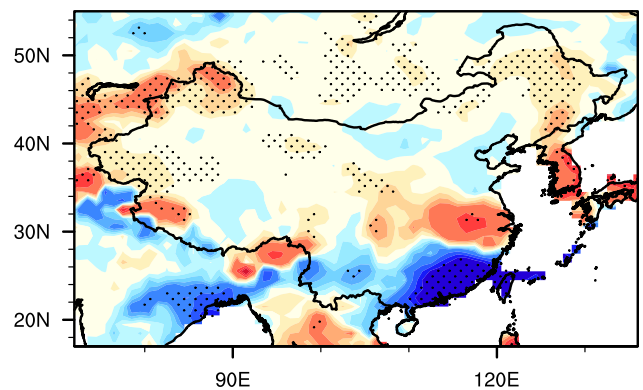

(d) AMJ

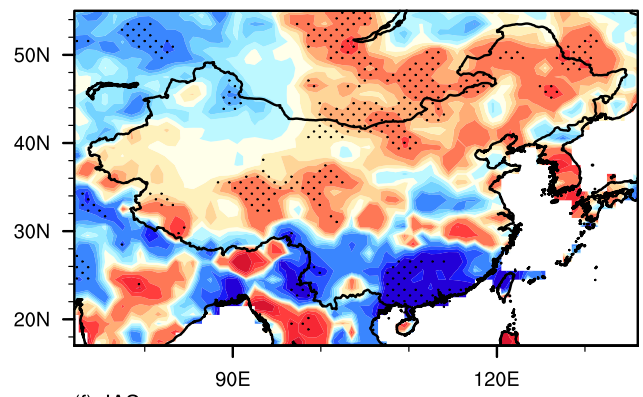

(f) JAS

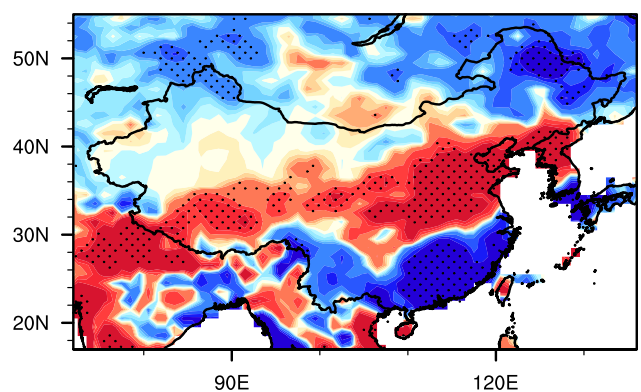

(h) OND

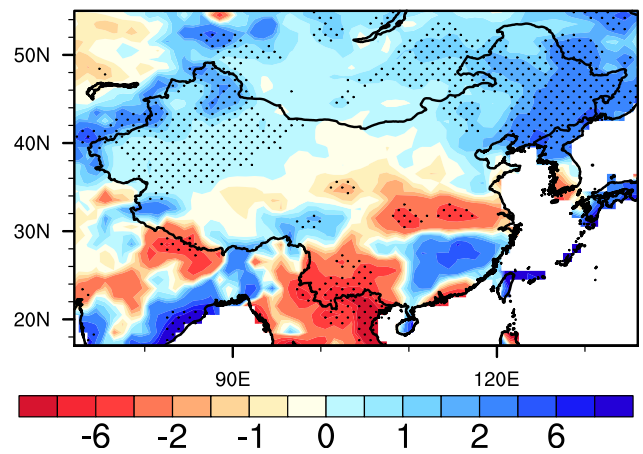

FIG. 7. The EC_S2 time series regressed against of (left) the vertically integrated (1000-300 hPa) water vapor flux (vectors; $\mathrm{kg} \mathrm{m}^{-1} \mathrm{~s}^{-1}$ ) and its divergence (shading; $10^{-6} \mathrm{~kg} \mathrm{~m}^{-2} \mathrm{~s}^{-1}$ ), and (right) the precipitation (mm month ${ }^{-1}$ ) for (a),(b) JFM, (c),(d) AMJ, (e),(f) JAS, and (g),(h) OND. All units are per unit standard deviation of the expansion coefficient. The dotted areas and green arrows indicate that the regressions are significant at the $95 \%$ confidence level of the Student's $t$ test.

strengthened Mongolian cold high ( $\mathrm{Li}$ and Bates 2007) increases the temperature (Fig. 8a) but decreases the precipitation (Fig. 7b) in northwestern and northeastern China and thus contributes to dry conditions in these regions (Fig. 3b).
In the spring, the anomalous northerly winds, associated with anomalous moisture flux divergence over northeastern China, suppress the water vapor transport to eastern and northern China but converge with the monsoonal southwesterlies over southeastern China 
(a) JFM

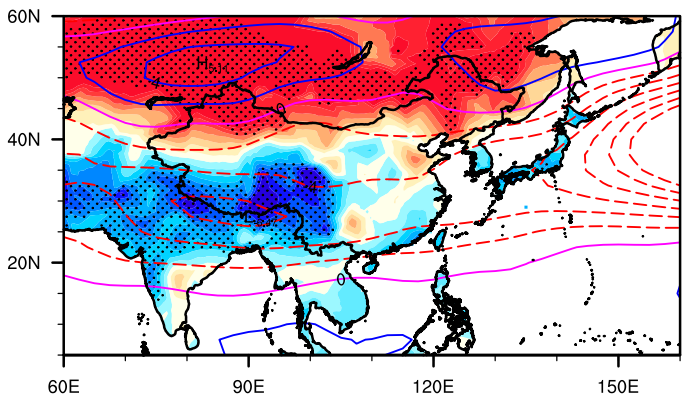
(c) JAS (b) AMJ

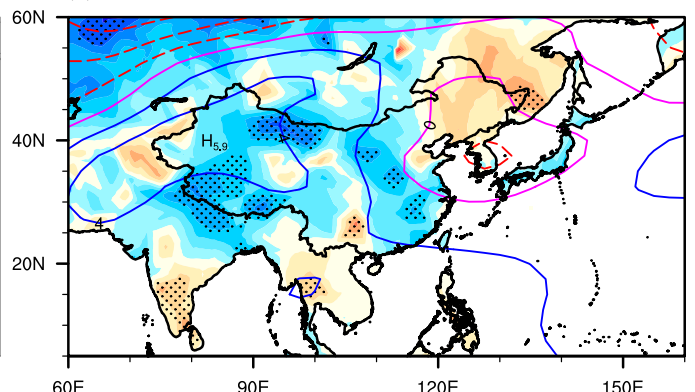

(d) OND

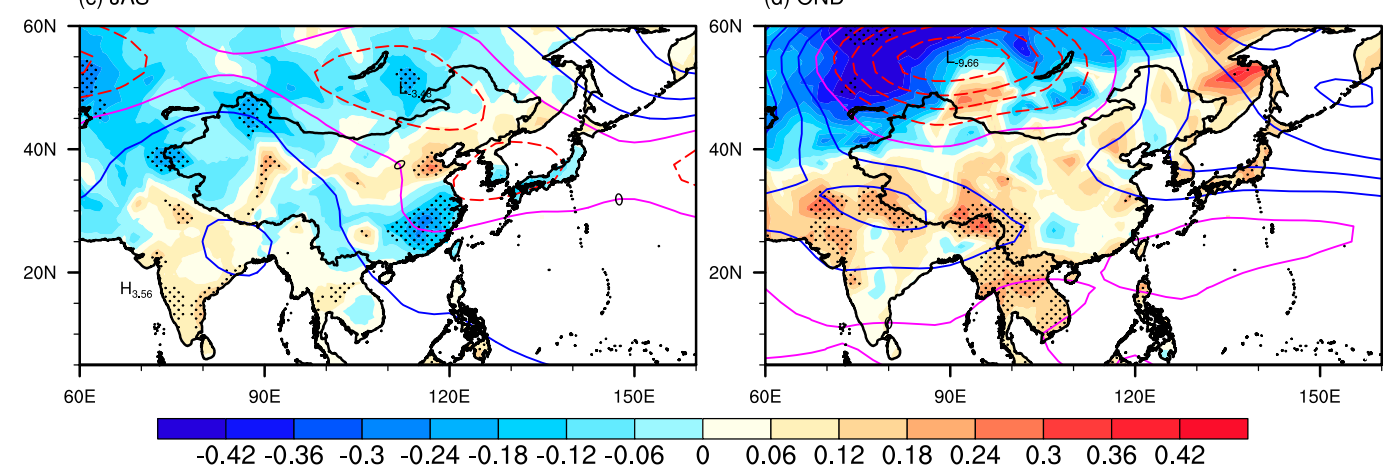

FIG. 8. The EC_S2 time series regressed against of temperature (shading; ${ }^{\circ} \mathrm{C}$ ) and geopotential height at $500 \mathrm{hPa}$ (Z500; contour; gpm) for (a) JFM, (b) AMJ, (c) JAS, and (d) OND. All units are per unit standard deviation of the expansion coefficient. The dotted areas indicate that the regressions of temperature are significant at the $95 \%$ confidence level of the Student's $t$ test. The solid and dashed lines indicate positive and negative values of Z500, respectively.

(Fig. 7c). Correspondingly, the reduced precipitation is found over the middle and lower reaches of the Yangtze River valley, North China, and Northeast China (Fig. 7d), resulting in a dryness condition in these regions (Fig. 4d). In contrast, the enhanced precipitation over southeastern China together with the cooling temperature contributes to the wetness conditions.

High values of summer EC2_S time series are associated with a tripole pattern of WVF in the three bands of convergence, divergence and convergence from southern China to northern China in the summer (Fig. 7e). The consequent precipitation patterns (Fig. 7f) follow areas of moisture convergence with positive regression values over southeastern China and the northern part of northwestern and northeastern China and suppressed precipitation over the remaining regions in the summer season (He et al. 2018). These spatial patterns project onto the positive phase of PDO/IPO and eastern Pacific warming. In addition, as shown in the EC2_P time series, the observed interdecadal changes of PDSI over China concur with the Pacific-wide interdecadal change in the late 1970s (e.g., Nitta and Yamada 1989; Trenberth and Hurrell 1994; Zhou et al. 2009b) and 1990s (e.g., Kwon et al. 2007; Wu et al. 2010). Both the spatial patterns and temporal variations suggest the possibility that the changes of dryness/wetness over China could be part of the largescale climate changes in relation to PDO/IPO.

Along with a westward shift of Pacific warming, there is an anomalous cyclone residing over the WNP instead of an anomalous anticyclone during the eastern Pacifictype El Niño developing in the autumn (Fig. 7g). The northerlies on the northwest flank of this cyclone decrease the moisture transport onto the Yangtze River valley, resulting in a drier-than-normal climate there (Zhang et al. 2011). Meanwhile, there is anomalous divergence of WVF over the Indo-China Peninsula and southwestern China, suppressing precipitation (Fig. 7h) and causing anomalous dry conditions there (Fig. 3h). Associated with the strengthened East Asian trough (Fig. 8d), a vast region over Mongolia, northwestern China, and northeastern China is subjected to moisture convergence (Fig. $7 \mathrm{~g}$ ), where the enhanced precipitation (Fig. 7h) and anomalous wet conditions are found correspondingly (Fig. 3h).

\section{Relationships between drought/wetness variability and climatic factors}

According to the SVD analysis, the IOBM, AMO, IPO, and Niño-4 indices have been recognized as the dominant climate factors that influence dryness/wetness 
(a) AMJ

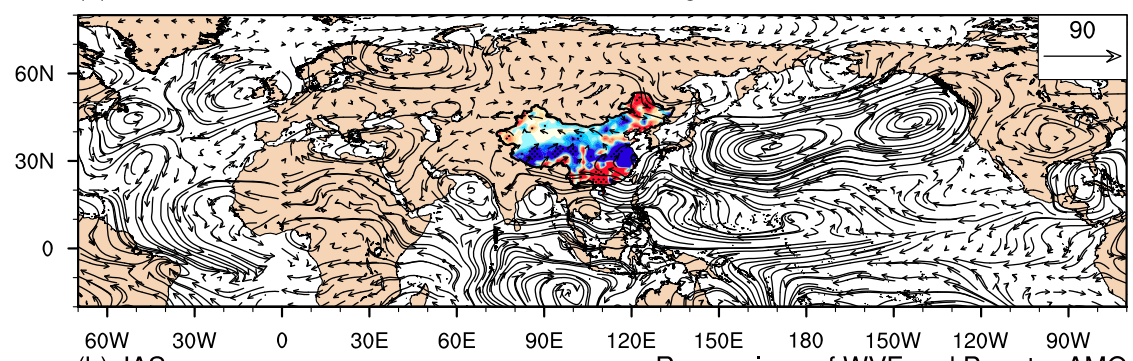

(b) JAS

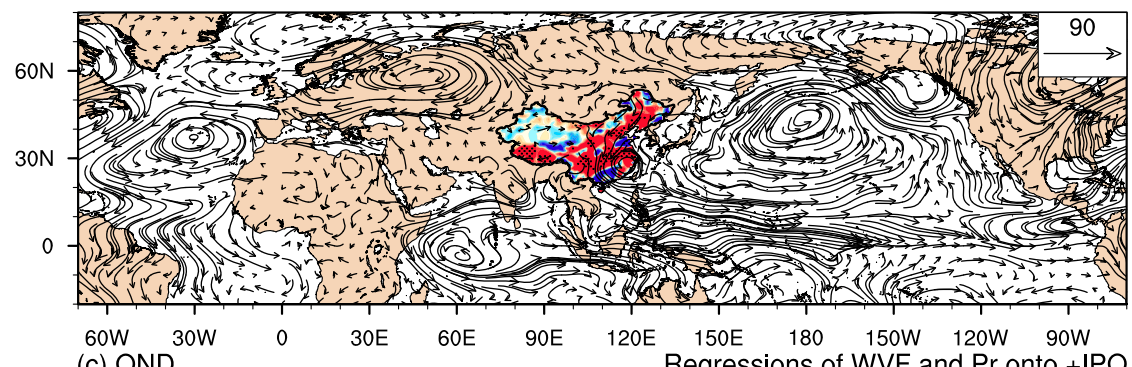

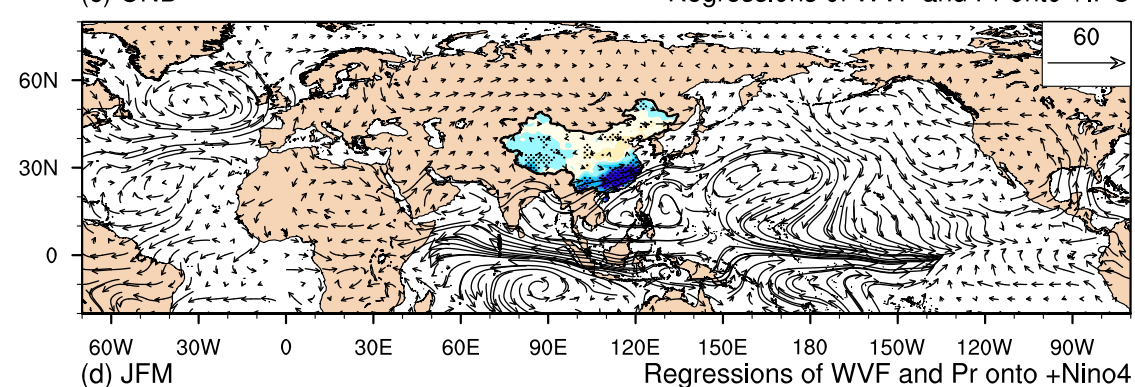

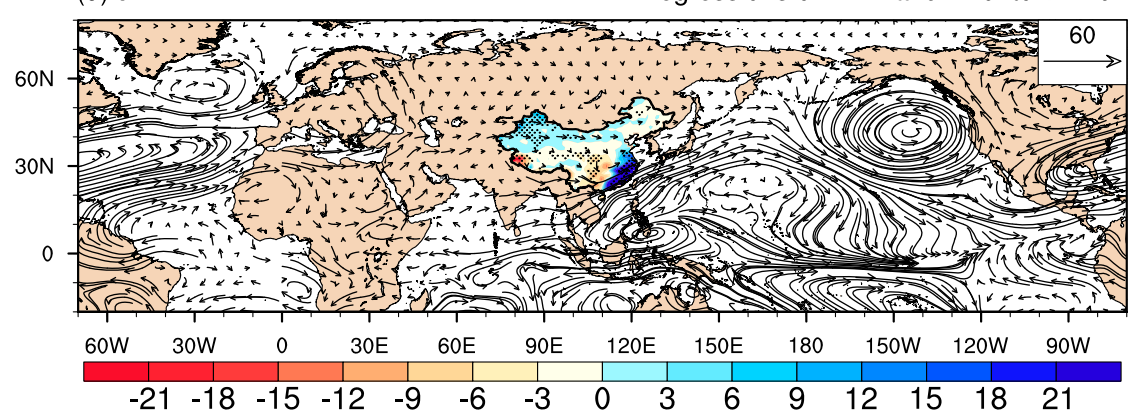

FIG. 9. Regressions of the vertically integrated (1000-300 hPa) water vapor flux (vectors; $\mathrm{kg} \mathrm{m}^{-1} \mathrm{~s}^{-1}$ ) and precipitation (shading; $\mathrm{mm}$ month ${ }^{-1}$ ) anomalies onto (a) the negative IOBM, (b) negative AMO, (c) positive IPO, and (d) positive Niño-4 during AMJ, JAS, OND, and JFM, respectively. The dotted areas indicate that the regressions of precipitation are significant at the $95 \%$ confidence level of the Student's $t$ test. Note that the signs of the regressed patterns in the negative values of indices are reversed (multiplied by -1 ) for clearer comparison with the positive values of indices.

variability in China in AMJ, JAS, OND, and JFM, respectively. Meanwhile, the main patterns of dryness/wetness in China displayed in the second SVD modes are primarily related to the AMO, IPO, IPO, and AMO in JFM, AMJ, JAS, and OND, respectively. To investigate to what extent the aforementioned PDSI anomaly patterns are due to the primary climate factors, we perform one-sided linear regression analysis corresponding to different cases selected in section 3. We first discuss the SVD1 case, and then the SVD2 case. In the SVD1 case, the leading climate indices are regressed onto precipitation in China and global WVF, respectively (Fig. 9). Specifically, the negative IOBM, negative AMO, positive IPO, and positive Niño-4 indices are used in AMJ, JAS, OND, and 
(a) JFM

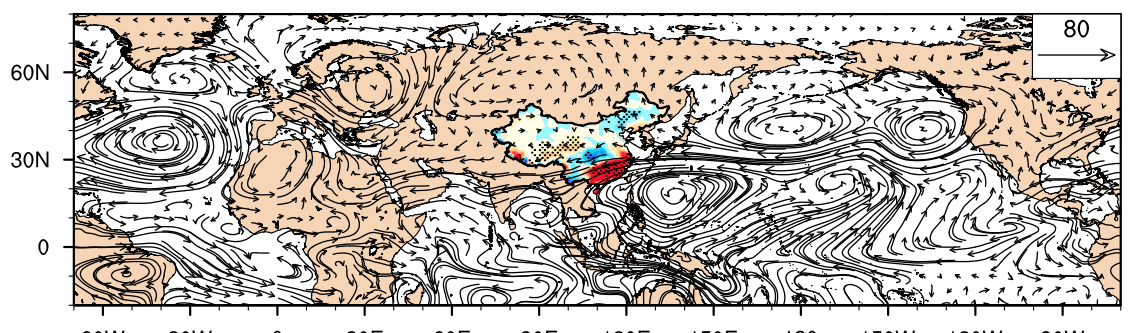

60W 30W $0 \quad 30 \mathrm{E} \quad 60 \mathrm{E} \quad 90 \mathrm{E} \quad 120 \mathrm{E} \quad 150 \mathrm{E} \quad 180 \quad 150 \mathrm{~W}$ 120W 90W

(b) AMJ Regressions of WVF and Pr onto +IPO
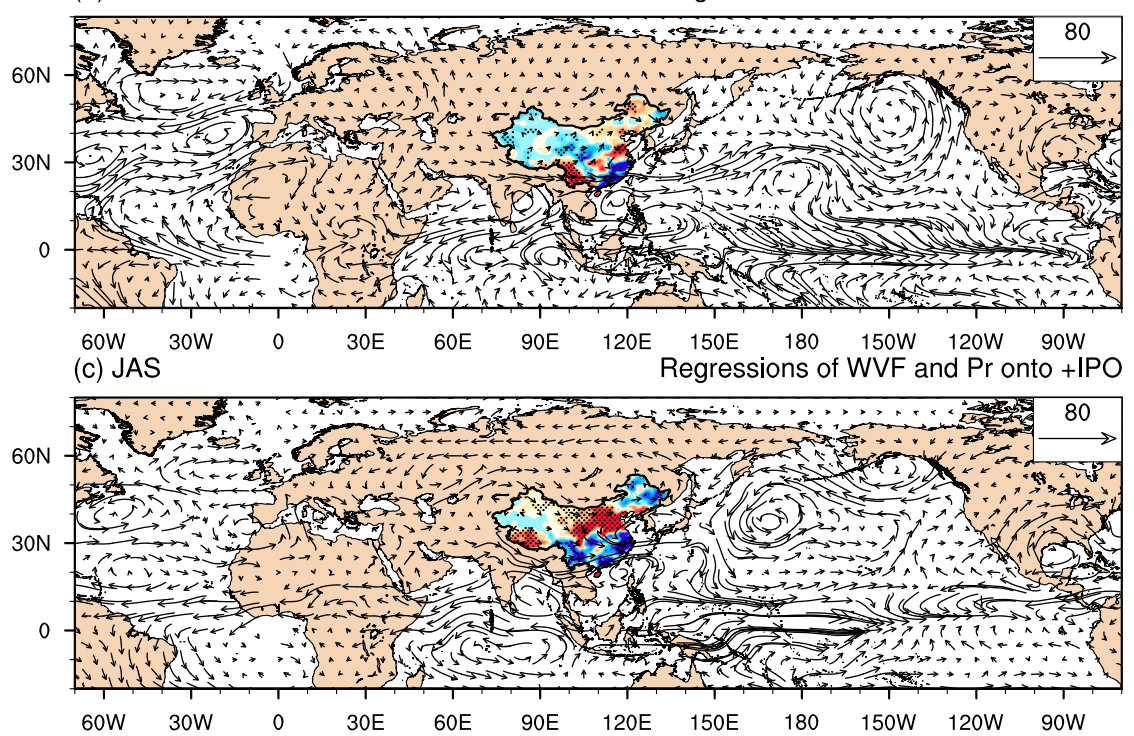

(d) OND $\quad$ Regressions of WVF and Pr onto +AMO

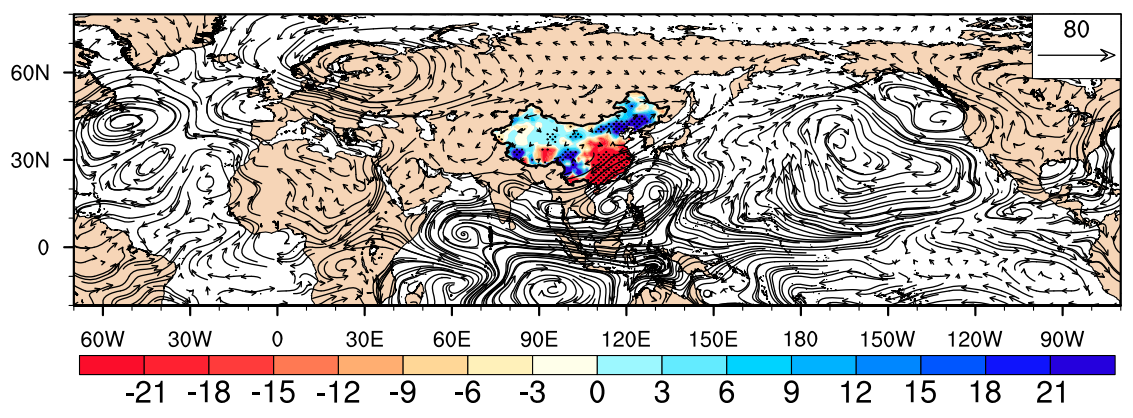

FIG. 10. Regressions of the vertically integrated $(1000-300 \mathrm{hPa})$ water vapor flux (vectors; $\mathrm{kg} \mathrm{m}^{-1} \mathrm{~s}^{-1}$ ) and precipitation (shading; $\mathrm{mm} \mathrm{month}^{-1}$ ) anomalies onto (a) the negative AMO, (b) positive IPO, (c) positive IPO, and (d) positive AMO during JFM, AMJ, JAS, and OND, respectively. The dotted areas indicate that the regressions of precipitation are significant at the $95 \%$ confidence level of the Student's $t$ test. Note that the sign of the regressed patterns in the negative values of indices are reversed (multiplied by -1 ) for clearer comparison with the positive values of indices.

JFM, respectively. In the SVD2 case, the negative AMO, positive IPO, positive IPO and positive AMO are regressed in JFM, AMJ, JAS, and OND, respectively (Fig. 10).

\section{a. First SVD}

For the SVD1 case, local convection over the tropical Indian Ocean is reduced during spring of negative phase of IOBM, inducing anomalous westerlies and leading to an enhanced cyclonic circulation over the SCS (Fig. 9a). The easterlies or northeasterlies on the northeast flank of this cyclone suppress the moisture transport into southeast China, decreasing rainfall there. Compared to the EC-regressed WVF (Fig. 5a), the IOBMrelated cyclone shows a westward shift. Meanwhile, a 
cyclonic anomaly of WVF is found over the Bay of Bengal, resulting in a convergence of moisture in southwestern China and wetter-than-normal conditions there. These results are in line with previous studies (Xie et al. 2009; Wu et al. 2010).

The regression pattern for the negative AMO in summer displays an evident wave-like structure in the middle (Z500; Fig. S2b) and higher troposphere (Z200; not shown) in the Northern Hemisphere. Significant negative height anomalies appear over the subtropical North Atlantic and a belt of negative height anomalies travels along the middle latitudes, with five significant negative nodes in western Europe, west-central Asia, East Asia, the North Pacific, and North America, respectively. This wave train pattern is close to the negative phase of circumglobal teleconnection (CGT) revealed in previous studies (Ding and Wang 2005; Saeed et al. 2011). Over central and eastern China, the northerlies prevail as part of the anomalous cyclone centered over northeastern China. This gives rise to an eastward contraction of the WNP subtropical high, reduces the EASM, and leads to less precipitation in these regions. Meanwhile, the northerlies converge with the weakened EASM in southwestern China, inducing more precipitation there.

During the autumn with a positive IPO index, there are anticyclonic anomalies over the SCS and cyclonic anomalies over Northeast Asia (Fig. 9c and Fig. S2c). Accordingly, anomalous cold and dry northeasterly and northerly winds are seen around North China, strengthening the EAT and reducing moisture over North China (Qin et al. 2018), whereas anomalous warm and wet southwesterly winds appear around southeastern China and enhance moisture there. Corresponding to the positive phase of Niño-4 during the winter, enhanced precipitation is found over both southeastern and northwestern China accompanied with westerly and southwesterly anomalies (Fig. 9d), which in turn transports more moisture from the tropical ocean into these regions.

\section{b. Second SVD}

For the SVD2 case, a zonal wave structure appears over the mid- to high latitudes during the winter of the AMO cold phase, with alternate centers of cyclonic and anticyclonic anomalies extending from the North Atlantic to East Asia at the middle troposphere (Fig. S3a). These are quite similar to the Atlantic-Eurasian (AEA) teleconnection (Li and Ruan 2018), or Africa-Asia multidecadal teleconnection (AAMT) pattern (Sun et al. 2017a; $\mathrm{Li}$ et al. 2019). Specifically, there is a dipole pattern of circulation with an anomalous cyclone over the subtropical WNP and anticyclone over the northwestern Pacific. Therefore, the northeasterly (southeasterly) anomalies control southern (northeastern) China, disfavoring (favoring) the moisture transport and leading to a drier (wetter) condition in this region. The cyclonic circulation over the subtropical WNP might be induced by the northwestern Indian Ocean cooling (not shown; Wang and Wu 2012), which is generated by the AMO cooling through an atmospheric teleconnection (Sun et al. 2017b; Sun et al. 2019). It should be noted that the AMO-induced precipitation pattern shows an almost opposite sign to the SVD2 mode in the winter (Figs. 3b and $7 \mathrm{~b}$ ). We speculate that the atmospheric responses in China to the AMO-related forcing may not be completely separated from the responses to other climate forcings.

In the spring, the spatial WVF pattern associated with positive IPO phase shows an anomalous anticyclone over the SCS and a cyclonic anomaly over Japan (Fig. 10b). That is, the northeasterly anomalies prevail the northern portion of eastern China and converge with the westerly anomalies over southeastern China, which reduce precipitation over North China and northeastern China but increase precipitation over southeastern China. The anomalous dry conditions move southward to central China as compared to its position over North China and northeastern China during the spring, accompanied with a westward shift of the anomalous anticyclone during the summer of the positive IPO phase (Fig. 10c).

During the autumn, the regression patterns of Z500 for the positive phase of the AMO are roughly the mirror image of those associated with the negative AMO in the summer (Fig. S2b), similar to the positive CGT pattern (Fig. S3d). That is, in the middle troposphere, six prominent "centers of action" occur over western Europe, European Russia, west-central Asia, east Asia, the North Pacific, and North America. In the lower troposphere, pronounced anomalous cyclonic flows appear over the Philippines. These anomalies can prevent moist and warm water vapor toward eastern China and give rise to a drier than normal condition there. This result is in agreement with previous studies (e.g., Li et al. 2015; Barcikowska et al. 2017; Sun et al. 2017b), which pointed out that the AMO warm SST anomaly could generate a coupled ocean-atmosphere teleconnection to the North Pacific, which induces a tropical North Pacific SST warming (Fig. 3g). In response to this warming, an anomalous cyclonic circulation appears over the tropical WNP region. Meanwhile, an anomalous anticyclonic circulation appears over the far northeast, as part of the CGT. Correspondingly, the southwesterly anomalies are over northeastern China, providing the moisture transport and leading to a wetter condition in this region.

In general, the dominant climate factors and the associated large-scale circulations might be responsible for the main covariability of the dryness/wetness (i.e., the 
seasonal movement of the drought) in China. Comparing the atmospheric responses to the negative and positive phases of the AMO in the autumn and winter, we suggest that the AMO exhibits asymmetric effects on the dryness/wetness changes in China. Moreover, the influence pathway of the AMO is season-dependent. It imposes a mid- to high-latitude pathway through the atmospheric bridge to propagate its modifying effects in the summer, autumn, and winter seasons. However, during the autumn and winter seasons, the AMO signal also exerts coupled ocean-atmosphere feedbacks in the western Pacific and Indian Oceans, modifying the anomalous cyclone over the subtropical WNP and then influencing the wetness/dryness changes in China.

\section{Conclusions and discussion}

Using the SVD analysis, we have performed a spatiotemporal decomposition of seasonal moisture variability in China and its relationship with global SSTA for the 65-yr period of 1950-2014. Then, based on the decomposed spatial patterns and the associated temporal patterns, the possible influences of ENSO, IPO, PDO, IOD, IOBM, and AMO on seasonal PDSI in China have been investigated. In addition, to elucidate the general mechanisms responsible for the connection between PDSI seasonal variability and global SSTA, we also have examined changes for the seasonal large-scale atmospheric circulation, precipitation, and temperature linked to PDSI variability.

As a comprehensive documentation of all the above results, it can be concluded that the first SVD mode of SSTA displays an eastern Pacific-type El Niño developing from the spring to winter over the tropical Pacific. That is, the SSTA is characterized by the warm phases of ENSO, IPO/PDO, and IOBM in the autumn and winter seasons. Meanwhile, a negative AMO phase is found during the spring and summer seasons, but a positive AMO pattern is observed in the winter. Following the SSTA pattern, there is a wet-dry dipole like pattern of PDSI between southwestern China and the rest of China in the spring. As the season progresses from the spring to winter, the wetter condition shifts eastward from southwestern to southeastern China, while the drier condition retreats from the northern parts of China to the central parts of China. Overall, interdecadal variations of summer and spring PDSI over China can be dominated by the AMO signal, while the IOBM may be a crucial factor in interannual variability of PDSI in the spring. During the autumn and winter seasons, PDSI variability seems to be closely associated with ENSO-related events.

The SSTA-related dryness/wetness anomalies shown in the first SVD modes can be explained by the associated anomaly circulations. During the spring, the large circulation is characterized by IOBM-induced cyclonic flows over the northeastern Philippine Sea, which leads to divergence of moisture and deficient precipitation over most parts of eastern China. Furthermore, the anomalous anticyclonic (cyclonic) moisture circulation appears over northern Northwest China and Russia (eastern TP), resulting in the increase (decrease) of temperature, decrease (increase) of precipitation, and consequently drier (wetter) conditions over northwestern and northeastern (southwestern) China. During the summer, the aforementioned anomalous cyclone of moisture over the northeast Philippine Sea shifts to the south Sea of Japan, as the southern part of the negative phase of EAP/PJ pattern, contributing to an outof-phase pattern of precipitation anomalies over eastern China. Meanwhile, the anomalous moisture divergence over southwestern China suppresses precipitation there. Afterward, the PSAC, possibly due to local air-sea interactions associated with the warm phase of ENSOrelated events, develops in the autumn and is maintained in the winter, transporting more warm and moist water vapor toward southeastern China and causing the abundant precipitation there. In the autumn, associated with the IPO-induced SST variation, the EAT is strengthened, which would cause below-normal precipitation over North China. In the winter, northwestern China becomes wetter with the anomalous moisture convergence.

The second SVD modes of SSTA display a central Pacific-type El Niño developing from the winter to autumn over the tropical Pacific and a positive phase of IPO or PDO from the winter to summer. Moreover, an AMO pattern is observed in all seasons except the summer, whereas the SST over the tropical Indian Ocean shows negligible changes. The spatial pattern associated with the second PDSI mode features a south-north seesaw pattern with a moisture surplus in southern China and a moisture deficit in the northern parts in the winter. With the season progressing from the winter to autumn, the drier conditions retreat southwestward to southwestern China, the western TP, and some regions in central China and southwestern China in the autumn. Correspondingly, increased moisture occurs in the northern parts of northwestern China during the spring and extends to the entirety of northern China in the autumn. In contrast, the wetter conditions over southern China weaken from the winter and almost dissipate in the autumn. Besides, the AMO has played a critical role in producing PDSI variability shown in the SVD2 mode during the autumn and winter seasons, whereas the ENSO-related (IPO) variability of SSTA in the Pacific dominates the corresponding PDSI patterns in the spring and summer seasons.

In regard to the large-scale atmospheric circulation, the anomalous anticyclonic moisture circulation over 
the south of the SCS is proposed as one of the causes of the increased water vapor transport and precipitation and anomalous wet conditions over the southern parts of China in the winter. Furthermore, the strengthened Mongolian cold high increases the temperature but decreases the precipitation in northwestern and northeastern China and correspondingly contributes to dry conditions in these regions. In the spring, a dryness condition is observed over the middle and lower reaches of the Yangtze River valley, North China, and Northeast China as a result of the reductive precipitation accompanied by the anomalous moisture flux divergence over northeastern China. In contrast, the enhanced precipitation together with the cooling temperature contributes to the wetness conditions over southeastern China. As part of the large-scale climate changes in relation to $\mathrm{PDO} / \mathrm{IPO}$, the precipitation patterns follow areas of moisture convergence over southeastern China and the northern part of northwestern and northeastern China and suppress precipitation over the remaining regions in summer seasons. In the autumn, AMO warm SST anomaly generates a coupled ocean-atmosphere teleconnection to the North Pacific, which induces a subtropical North Pacific SST warming. In response to this warming, an anomalous cyclonic circulation appears over the subtropical WNP region. The corresponding northeasterly anomalies suppress the moisture transport onto the Yangtze River valley and thus decrease precipitation there.

The major findings of the current study are that the leading SVD modes of PDSI-SSTA covariability and their relationship with the large-scale atmospheric circulation vary from one season to another. Also, the results in the study point out on how complex drivers of dryness/wetness variability at the national and regional scale in China are. Besides, the seasonal variations of PDSI in China are related to transitions of global SSTA, especially the dominant climate factors. In summary, these findings will provide valuable information for improving the long-term forecasting of dryness/wetness based on the relationship with ENSO, IPO/PDO, IOD/ IOBM, and AMO. In addition, the results will be helpful for improving decision support and drought/flood mitigation and planning and development of agricultural activities under influences of natural climate variability. However, further investigation is required in the future to better understand the underlying physical mechanisms.

Acknowledgments. This work was supported by the National Key Research and Development Program of China (2016YFA0600402 and 2019YFA0606701), the National Natural Science Foundation of China (41790475, 41731173, and 41605066), the Pioneer Hundred Talents Program of the Chinese Academy of Sciences, the Leading
Talents of Guangdong Province Program, and the Strategic Priority Research Program of the Chinese Academy of Sciences (XDA20060502).

\section{REFERENCES}

Ahn, Y. I., and D. K. Lee, 2002: Impact of bogus tropical cyclones on summertime circulation in regional climate simulation. J. Geophys. Res., 107, 4303, https://doi.org/10.1029/2001JD000416.

Akinremi, O. O., S. M. McGinn, and A. G. Barr, 1996: Evaluation of the Palmer drought index on the Canadian prairies. J. Climate, 9, 897-905, https://doi.org/10.1175/ 1520-0442(1996)009<0897:EOTPDI > 2.0.CO;2.

Alley, W. M., 1984: The Palmer drought severity index: Limitations and applications. J. Climate Appl. Meteor., 23, 1100-1109, https://doi.org/10.1175/1520-0450(1984)023<1100:TPDSIL> 2.0.CO;2.

Barcikowska, M. J., T. R. Knutson, and R. Zhang, 2017: Observed and simulated fingerprints of multidecadal climate variability and their contributions to periods of global SST stagnation. J. Climate, 30, 721-737, https://doi.org/10.1175/JCLI-D-160443.1.

Bretherton, C. S., C. Smith, and J. M. Wallace, 1992: An intercomparison of methods for finding coupled patterns in climate data. J. Climate, 5, 541-560, https://doi.org/10.1175/ 1520-0442(1992)005<0541:AIOMFF > 2.0.CO;2.

Chan, J. C. L., and W. Zhou, 2005: PDO, ENSO and the early summer monsoon rainfall over South China. Geophys. Res. Lett., 32, L08810, https://doi.org/10.1029/2004GL022015.

Chen, W., H. Graf, and R. H. Huang, 2000: The interannual variability of East Asian winter monsoon and its relation to the summer monsoon. Adv. Atmos. Sci., 17, 48-60, https://doi.org/ 10.1007/s00376-000-0042-5.

Dai, A., 2011a: Drought under global warming: A review. Wiley Interdiscip. Rev.: Climate Change, 2, 45-65, https://doi.org/ 10.1002/wcc. 81 .

- 2011b: Characteristics and trends in various forms of the Palmer Drought Severity Index during 1900-2008. J. Geophys. Res., 116, D12115, https://doi.org/10.1029/2010JD015541.

, 2013: The influence of the inter-decadal Pacific oscillation on US precipitation during 1923-2010. Climate Dyn., 41, 633-646, https://doi.org/10.1007/s00382-012-1446-5.

Dee, D. P., and Coauthors, 2011: The ERA-Interim reanalysis: Configuration and performance of the data assimilation system. Quart. J. Roy. Meteor. Soc., 137, 553-597, https://doi.org/ 10.1002/qj.828.

Ding, Q. H., and B. Wang, 2005: Circumglobal teleconnection in the Northern Hemisphere summer. J. Climate, 18, 3483-3505, https://doi.org/10.1175/JCLI3473.1.

Feng, J., W. Chen, C. Y. Tam, and W. Zhou, 2011: Different impacts of El Niño and El Niño Modoki on China rainfall in the decaying phases. Int. J. Climatol., 31, 2091-2101, https:// doi.org/10.1002/joc.2217.

Guan, Z., and T. Yamagata, 2003: The unusual summer of 1994 in East Asia: IOD teleconnections. Geophys. Res. Lett., 30, 1544 , https://doi.org/10.1029/2002GL016831.

Hao, X., and S. He, 2017: Combined effect of ENSO-like and Atlantic multidecadal oscillation SSTAs on the interannual variability of the East Asian winter monsoon. J. Climate, 30, 2697-2716, https://doi.org/10.1175/JCLI-D-16-0118.1.

Harris, I., P. D. Jones, T. J. Osborn, and D. H. Lister, 2014: Updated high-resolution grids of monthly climatic observations-The 
CRU TS3.10 dataset. Int. J. Climatol., 34, 623-642, https:// doi.org/10.1002/joc.3711.

He, S. P., Y. Q. Gao, T. Furevik, H. J. Wang, and F. Li, 2018: Teleconnection between sea ice in the Barents Sea in June and the Silk Road, Pacific-Japan and East Asian rainfall patterns in August. Adv. Atmos. Sci., 35, 52-64, https://doi.org/10.1007/ s00376-017-7029-y.

Heim, R. R., Jr., 2002: A review of twentieth-century drought indices used in the United States. Bull. Amer. Meteor. Soc., 83, 1149-1165, https://doi.org/10.1175/1520-0477-83.8.1149.

Hu, Z., 1997: Interdecadal variability of summer climate over East Asia and its association with $500 \mathrm{hPa}$ height and global sea surface temperature. J. Geophys. Res., 102, 19403-19412, https://doi.org/10.1029/97JD01052.

Huang, R. H., 1992: The East Asia/Pacific pattern teleconnection of summer circulation and climate anomaly in East Asia. J. Meteor. Res., 6, 25-37.

Hubacek, K., D. Guan, and A. Barua, 2007: Changing lifestyles and consumption patterns in developing countries: A scenario analysis for China and India. Futures, 39, 1084-1096, https:// doi.org/10.1016/j.futures.2007.03.010.

Karl, T. R., 1986: The sensitivity of the Palmer Drought Severity Index and Palmer's Z-index to their calibration coefficients including potential evapotranspiration. J. Climate Appl. Meteor., 25, 77-86, https://doi.org/10.1175/1520-0450(1986)025<0077:TSOTPD> 2.0.CO;2.

Kim, J.-W., S.-W. Yeh, and E.-C. Chang, 2014: Combined effect of El Niño-Southern Oscillation and Pacific decadal oscillation on the East Asian winter monsoon. Climate Dyn., 42, 957-971, https://doi.org/10.1007/s00382-013-1730-z.

Kwon, M., J.-G. Jhun, and K.-J. Ha, 2007: Decadal change in East Asian summer monsoon circulation in the mid-1990s. Geophys. Res. Lett., 34, L21706, https://doi.org/10.1029/ 2007 GL031977.

Li, C.-X., C. Wang, and T. Zhao, 2018: Influence of two types of ENSO events on tropical cyclones in the western North Pacific during the subsequent year: Asymmetric response. Climate Dyn., 51, 2637-2655, https://doi.org/10.1007/s00382-017-4033-y.

Li, C.-Y., 1990: Interaction between anomalous winter monsoon in East Asia and El Niño events. Adv. Atmos. Sci., 7, 36-46, https://doi.org/10.1007/BF02919166.

— on atmospheric circulation and climate. Adv. Atmos. Sci., 18, 831-843, https://doi.org/10.1007/BF03403506.

Li, H., A. Dai, T. Zhou, and J. Lu, 2010: Responses of East Asian summer monsoon to historical SST and atmospheric forcing during 1950-2000. Climate Dyn., 34, 501-514, https://doi.org/ 10.1007/s00382-008-0482-7.

Li, J. P., and C. Q. Ruan, 2018: The North Atlantic-Eurasian teleconnection in summer and its effects on Eurasian climates. Environ. Res. Lett., 13, 024007, https://doi.org/10.1088/1748-9326/aa9d33.

_, F. Zheng, C. Sun, J. Feng, and J. Wang, 2019: Pathways of influence of the Northern Hemisphere mid-high latitudes on East Asian climate: A review. Adv. Atmos. Sci., 36, 902-921, https://doi.org/10.1007/s00376-019-8236-5.

Li, S. L., and G. T. Bates, 2007: Influence of the Atlantic multidecadal oscillation on the winter climate of East China. Adv. Atmos. Sci., 24, 126-135, https://doi.org/10.1007/s00376007-0126-6.

Li, X., W. Zhou, D. Chen, C. Li, and J. Song, 2014: Water vapor transport and moisture budget over eastern China: Remote forcing from the two types of El Niño. J. Climate, 27, 87788792, https://doi.org/10.1175/JCLI-D-14-00049.1.
,-- , and Y. D. Chen, 2015: Assessment of regional drought trend and risk over China: A drought climate division perspective. J. Climate, 28, 7025-7037, https://doi.org/10.1175/ JCLI-D-14-00403.1.

Liu, Z., 2012: Dynamics of interdecadal climate variability: A historical perspective. J. Climate, 25, 1963-1995, https://doi.org/ 10.1175/2011JCLI3980.1.

Ma, Z., 2007: The interdecadal trend and shift of dry/wet over the central part of North China and their relationship to the Pacific decadal oscillation (PDO). Chin. Sci. Bull., 52, 2130-2139, https://doi.org/10.1007/s11434-007-0284-z.

Mantua, N. J., S. R. Hare, Y. Zhang, J. M. Wallace, and R. C. Francis, 1997: A Pacific interdecadal climate oscillation with impacts on salmon production. Bull. Amer. Meteor. Soc., 78, 1069-1079, https://doi.org/10.1175/1520-0477(1997)078<1069:APICOW> 2.0.CO;2.

Mao, J., J. C. L. Chan, and G. Wu, 2011: Interannual variations of early summer monsoon rainfall over South China under different PDO backgrounds. Int. J. Climatol., 31, 847-862, https:// doi.org/10.1002/joc.2129.

Ministry of Water Resources of the People's Republic of China, 2017: Bulletin of flood and drought disaster in China (in Chinese). SinoMaps Press, 82-87.

Mu, Q., M. Zhao, J. S. Kimball, N. G. McDowell, and S. W. Running, 2013: A remotely sensed global terrestrial drought severity index. Bull. Amer. Meteor. Soc., 94, 83-98, https:// doi.org/10.1175/BAMS-D-11-00213.1.

Nitta, T., 1987: Convective activities in the tropical western Pacific and their impact on the Northern Hemisphere summer circulation. J. Meteor. Soc. Japan, 65, 373-390, https://doi.org/ 10.2151/jmsj1965.65.3_373.

_, and S. Yamada, 1989: Recent warming of tropical sea surface temperature and its relationship to the Northern Hemisphere circulation. J. Meteor. Soc. Japan, 67, 375-383, https://doi.org/ 10.2151/jmsj1965.67.3_375.

Ohba, M., and H. Ueda, 2009: Role of nonlinear atmospheric response to SST on the asymmetric transition process of ENSO. J. Climate, 22, 177-192, https://doi.org/10.1175/2008JCLI2334.1.

Ouyang, R., W. Liu, G. Fu, C. Liu, L. Hu, and H. Wang, 2014: Linkages between ENSO/PDO signals and precipitation, streamflow in China during the last 100 years. Hydrol. Earth Syst. Sci., 18, 3651-3661, https://doi.org/10.5194/hess-18-3651-2014.

Palmer, W. C., 1965: Meteorological drought. U.S. Department of Commerce Research Paper 45, 65 pp.

Piao, S. L., and Coauthors, 2010: The impacts of climate change on water resources and agriculture in China. Nature, 467, 43-51, https://doi.org/10.1038/nature09364.

Power, S., T. Casey, C. Folland, A. Colman, and V. Mehta, 1999: Interdecadal modulation of the impact of ENSO on Australia. Climate Dyn., 15, 319-324, https://doi.org/10.1007/ s003820050284.

Qian, C., and T. Zhou, 2014: Multidecadal variability of north China aridity and its relationship to PDO during 19002010. J. Climate, 27, 1210-1222, https://doi.org/10.1175/ JCLI-D-13-00235.1.

—_, Y. Yu, and G. Chen, 2014: Decadal summer drought frequency in China: The increasing influence of the Atlantic multi-decadal oscillation. Environ. Res. Lett., 9, 124004, https://doi.org/ 10.1088/1748-9326/9/12/124004.

Qin, M., D. Li, A. Dai, W. Hua, and H. Ma, 2018: The influence of the Pacific decadal oscillation on north central China precipitation during boreal autumn. Int. J. Climatol., 38 (Suppl.1), e821-e831, https://doi.org/10.1002/joc.5410. 
Qiu, Y., W. Cai, X. Guo, and B. Ng, 2014: The asymmetric influence of the positive and negative IOD events on China's rainfall. Sci. Rep., 4, 4943, https://doi.org/10.1038/SREP04943.

Rayner, N. A., and Coauthors, 2003: Global analyses of sea surface temperature, sea ice, and night marine air temperature since the late nineteenth century. J. Geophys. Res., 108, 4407, https://doi.org/10.1029/2002JD002670.

Saeed, S., W. A. Muller, S. Hagemann, and D. Jacob, 2011: Circumglobal wave train and the summer monsoon over northwestern India and Pakistan: The explicit role of the surface heat low. Climate Dyn., 37, 1045-1060, https:// doi.org/10.1007/s00382-010-0888-x.

Shabbar, A., and W. Skinner, 2004: Summer drought patterns in Canada and the relationship to global sea surface temperatures. J. Climate, 17, 2866-2880, https://doi.org/10.1175/ 1520-0442(2004)017<2866:SDPICA >2.0.CO;2.

Simmons, A. J., and J. K. Gibson, 2000: The ERA-40 Project Plan. ERA-40 Project Rep. Series No. 1, ECMWF, 63 pp., https:// www.ecmwf.int/sites/default/files/elibrary/2000/12272-era40-project-plan.pdf.

Soulé, P. T., 1992: Spatial patterns of drought frequency and duration in the contiguous USA based on multiple drought event definitions. Int. J. Climatol., 12, 11-24, https://doi.org/10.1002/ joc.3370120103.

Stuecker, M. F., F.-F. Jin, A. Timmermann, and S. McGregor, 2015: Combination mode dynamics of the anomalous northwest Pacific anticyclone. J. Climate, 28, 1093-1111, https://doi.org/ 10.1175/JCLI-D-14-00225.1.

Sun, C., J. Li, R. Ding, and Z. Jin, 2017a: Cold season Africa-Asia multidecadal teleconnection pattern and its relation to the Atlantic multidecadal variability. Climate Dyn., 48, 3903-3918, https://doi.org/10.1007/s00382-016-3309-y.

, F. Kucharski, J. Li, F.-F. Jin, I.-S. Kang, and R. Ding, 2017b: Western tropical Pacific multidecadal variability forced by the Atlantic multidecadal oscillation. Nature Commun., 8, 15998, https://doi.org/10.1038/ncomms15998.

— warming induced by the Atlantic-western Pacific trans-basin multidecadal variability. Geophys. Res. Lett., 46, 1662-1671, https://doi.org/10.1029/2018GL081175.

Trenberth, K. E., and J. W. Hurrell, 1994: Decadal atmosphereocean variations in the Pacific. Climate Dyn., 9, 303-319, https://doi.org/10.1007/BF00204745.

van der Schrier, G., P. D. Jones, and K. R. Briffa, 2011: The sensitivity of the PDSI to the Thornthwaite and PenmanMonteith parameterizations for potential evapotranspiration. J. Geophys. Res., 116, D03106, https://doi.org/10.1029/ 2010JD015001.

Varis, O., and P. Vakkilainen, 2001: China's 8 challenges to water resources management in the first quarter of the 21st century. Geomorphology, 41, 93-104, https://doi.org/10.1016/S0169555X(01)00107-6.

Vicente-Serrano, S. M., S. Beguería, and J. I. López-Moreno, 2011: Comment on "Characteristics and trends in various forms of the Palmer Drought Severity Index (PDSI) during 1900-2008", by Aiguo Dai. J. Geophys. Res., 116, D19112, https://doi.org/ 10.1029/2011JD016410.

Wallace, J. M., C. Smith, and C. S. Bretherton, 1992: Singular value decomposition of wintertime sea surface temperature and 500-mb height anomalies. J. Climate, 5, 561-576, https://doi.org/ 10.1175/1520-0442(1992)005<0561:SVDOWS > 2.0.CO;2.

Wang, B., and Q. Zhang, 2002: Pacific-East Asian teleconnection. Part II: How the Philippine Sea anomalous anticyclone is established during El Niño development. J. Climate, 15, 32523265, https://doi.org/10.1175/1520-0442(2002)015<3252: PEATPI $>2.0 . \mathrm{CO} ; 2$.

$\longrightarrow$, R. Wu, and X. Fu, 2000: Pacific-East Asian teleconnection: How does ENSO affect East Asian climate? J. Climate, 13, 1517-1536. https://doi.org/10.1175/1520-0442(2000)013<1517: PEATHD $>2.0 . C O ; 2$.

Wang, C., and X. Wang, 2013: Classifying El Niño Modoki I and II by different impacts on rainfall in southern China and typhoon tracks. J. Climate, 26, 1322-1338, https://doi.org/10.1175/JCLID-12-00107.1.

_ , R. H. Weisberg, and J. Virmani, 1999: Western Pacific interannual variability associated with the El Niño-Southern Oscillation. J. Geophys. Res., 104, 5131-5149, https://doi.org/ 10.1029/1998JC900090.

Wang, H., and S. He, 2015: The north China/northeastern Asia severe summer drought in 2014. J. Climate, 28, 6667-6681, https://doi.org/10.1175/JCLI-D-15-0202.1.

Wang, L., and R. Wu, 2012: In-phase transition from the winter monsoon to the summer monsoon over East Asia: Role of the Indian Ocean. J. Geophys. Res., 117, D11112, https://doi.org/ 10.1029/2012JD017509.

Weber, L., and L. C. Nkemdirim, 1998: Palmer's drought indices revisited. Geogr. Ann., 80A, 153-172, https://doi.org/10.1111/ j.0435-3676.1998.00033.x.

Wells, N., S. Goddard, and M. J. Hayes, 2004: A self-calibrating Palmer drought severity index. J. Climate, 17, 23352351, https://doi.org/10.1175/1520-0442(2004)017<2335: ASPDSI $>2.0 . \mathrm{CO} ; 2$.

Weng, H., G. Wu, Y. Liu, S. K. Behera, and T. Yamagata, 2011: Anomalous summer climate in China influenced by the tropical Indo-Pacific Oceans. Climate Dyn., 36, 769-782, https:// doi.org/10.1007/s00382-009-0658-9.

Wu, B., T. Li, and T. Zhou, 2010: Relative contributions of the Indian Ocean and local SST anomalies to the maintenance of the western North Pacific anomalous anticyclone during the El Niño decaying summer. J. Climate, 23, 2974-2986, https:// doi.org/10.1175/2010JCLI3300.1.

Wu, R., Z.-Z. Hu, and B. P. Kirtman, 2003: Evolution of ENSO-related rainfall anomalies in East Asia. J. Climate, 16, 3742-3758, https:// doi.org/10.1175/1520-0442(2003)016<3742:EOERAI > 2.0.CO;2.

Xiao, M., Q. Zhang, and V. Singh, 2015: Influences of ENSO, NAO, IOD and PDO on seasonal precipitation regimes in the Yangtze River basin, China. Int. J. Climatol., 35, 3556-3567, https://doi.org/10.1002/joc.4228.

Xie, S., K. Hu, J. Hafner, H. Tokinaga, Y. Du, G. Huang, and T. Sampe, 2009: Indian Ocean capacitor effect on Indowestern Pacific climate during the summer following El Niño. J. Climate, 22, 730-747, https://doi.org/10.1175/2008JCLI2544.1.

Yang, J., Q. Liu, S.-P. Xie, Z. Liu, and L. Wu, 2007: Impact of the Indian Ocean SST basin mode on the Asian summer monsoon. Geophys. Res. Lett., 34, L02708, https://doi.org/10.1029/ 2006 GL028571.

Yuan, Y., and S. Yang, 2012: Impacts of different types of El Niño on the East Asian climate: Focus on ENSO cycles. J. Climate, 25, 7702-7722, https://doi.org/10.1175/JCLI-D11-00576.1.

Zhai, J., B. Su, V. Krysanova, T. Vetter, C. Gao, and T. Jiang, 2010: Spatial variation and trends in PDSI and SPI indices and their relation to streamflow in 10 large regions of China. J. Climate, 23, 649-663, https://doi.org/10.1175/2009JCLI2968.1.

Zhang, W., F.-F. Jin, J. Li, and H. Ren, 2011: Contrasting impacts of two-type El Niño over the western North Pacific during boreal 
autumn. J. Meteor. Soc. Japan, 89, 563-569, https://doi.org/ 10.2151/jmsj.2011-510.

, and A. Turner, 2014: Increasing autumn drought over southern China associated with ENSO regime shift. Geophys. Res. Lett., 41, 4020-4026, https://doi.org/10.1002/2014GL060130.

— , H. Li, F.-F. Jin, M. Stuecker, A. Turner, and N. Klingaman, 2015: The annual-cycle modulation of meridional asymmetry in ENSO's atmospheric response and its dependence on ENSO zonal structure. J. Climate, 28, 5795-5812, https:// doi.org/10.1175/JCLI-D-14-00724.1.

Zhang, Y., J. M. Wallace, and D. S. Battisti, 1997: ENSO-like interdecadal variability: 1900-1993. J. Climate, 10, 1004-1020, https://doi.org/10.1175/1520-0442(1997)010<1004:ELIV> 2.0.CO;2.

Zhang, Y.-X., M. Wu, and D. Li, 2017: Spatiotemporal decompositions of summer drought in China and its teleconnection with global sea surface temperatures during 1901-2012. J. Climate, 30, 6391-6412, https://doi.org/10.1175/JCLI-D-16-0405.1.

Zhao, T., and A. Dai, 2015: The magnitude and causes of global drought changes in the twenty-first century under a low-moderate emissions scenario. J. Climate, 28, 4490-4512, https://doi.org/10.1175/JCLI-D-14-00363.1.

Zhou, L., and R. Huang, 2009: Interdecadal variability of summer rainfall in Northwest China and its possible causes. Int. J. Climatol., 30, 549-557, https://doi.org/10.1002/ JOC.1923.

Zhou, T., and Coauthors, 2009a: Why the western Pacific subtropical high has extended westward since the late 1970s. J. Climate, 22, 2199-2215, https://doi.org/10.1175/2008JCLI2527.1.

—, D. Gong, J. Li, and B. Li, 2009b: Detecting and understanding the multi-decadal variability of the East Asian summer monsoon-Recent progress and state of affairs. Meteor. Z., 18, 455467, https://doi.org/10.1127/0941-2948/2009/0396.

Zhou, W., C. Li, and J. C. L. Chan, 2006: The interdecadal variations of the summer monsoon rainfall over south China. Meteor. Atmos. Phys., 93, 165-175, https://doi.org/10.1007/ s00703-006-0184-9.

Zou, X., P. Zhai, and Q. Zhang, 2005: Variations in droughts over China: 1951-2003. Geophys. Res. Lett., 32, L04707, https:// doi.org/10.1029/2004GL021853. 